\title{
Valence and lowest Rydberg electronic states of phenol investigated by synchrotron radiation and theoretical methods
}

P. Limão-Vieira, D. Duflot, F. Ferreira da Silva, E. Lange, N. C. Jones, S. V. Hoffmann, M. A. Śmiałek, D. B. Jones, and M. J. Brunger

Citation: The Journal of Chemical Physics 145, 034302 (2016); doi: 10.1063/1.4955334

View online: https://doi.org/10.1063/1.4955334

View Table of Contents: http://aip.scitation.org/toc/jcp/145/3

Published by the American Institute of Physics

\section{Articles you may be interested in}

An experimental and theoretical investigation into the excited electronic states of phenol

The Journal of Chemical Physics 141, 074314 (2014); 10.1063/1.4893116

High resolution photofragment translational spectroscopy studies of the near ultraviolet photolysis of phenol

The Journal of Chemical Physics 125, 133318 (2006); 10.1063/1.2353818

Excited state hydrogen transfer dynamics in substituted phenols and their complexes with ammonia:

$\pi \pi^{*}-\pi \sigma^{*}$ energy gap propensity and ortho-substitution effect

The Journal of Chemical Physics 133, 124313 (2010); 10.1063/1.3480396

Advantage of spatial map ion imaging in the study of large molecule photodissociation

The Journal of Chemical Physics 147, 013904 (2017); 10.1063/1.4975671

Elastic scattering and vibrational excitation for electron impact on para-benzoquinone

The Journal of Chemical Physics 147, 244304 (2017); 10.1063/1.5010831

Time-resolved photoelectron imaging of excited state relaxation dynamics in phenol, catechol, resorcinol, and hydroquinone

The Journal of Chemical Physics 137, 184304 (2012); 10.1063/1.4765104

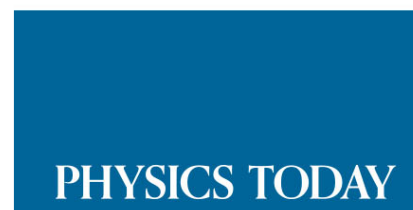

WHITEPAPERS
ADVANCED LIGHT CURE ADHESIVES

Take a closer look at what these environmentally friendly adhesive systems can do
READ NOW

PRESENTED BY

Q. MASTERBOND० 


\title{
Valence and lowest Rydberg electronic states of phenol investigated by synchrotron radiation and theoretical methods
}

\author{
P. Limão-Vieira, ${ }^{1, a)}$ D. Duflot, ${ }^{2,3}$ F. Ferreira da Silva, ${ }^{1}$ E. Lange,${ }^{1}$ N. C. Jones,${ }^{4}$ \\ S. V. Hoffmann, ${ }^{4}$ M. A. Śmiałek, ${ }^{5,6}$ D. B. Jones, ${ }^{7}$ and M. J. Brunger ${ }^{7,8}$ \\ ${ }^{1}$ Laboratório de Colisões Atómicas e Moleculares, CEFITEC, Departamento de Física, \\ Faculdade de Ciências e Tecnologia, Universidade NOVA de Lisboa, 2829-516 Caparica, Portugal \\ ${ }^{2}$ Univ. Lille, UMR 8523-Physique des Lasers Atomes et Molécules, F-59000 Lille, France \\ ${ }^{3}$ CNRS, UMR 8523, F-59000 Lille, France \\ ${ }^{4}$ ISA, Department of Physics and Astronomy, Aarhus University, Ny Munkegade 120, \\ DK-8000 Aarhus C, Denmark \\ ${ }^{5}$ Department of Control and Power Engineering, Faculty of Ocean Engineering and Ship Technology, \\ Gdańsk University of Technology, Gabriela Narutowicza 11/12, 80-233 Gdańsk, Poland \\ ${ }^{6}$ Department of Physical Sciences, The Open University, Walton Hall, MK7 6AA Milton Keynes, \\ United Kingdom \\ ${ }^{7}$ School of Chemical and Physical Sciences, Flinders University, GPO Box 2100, Adelaide, SA 5001, Australia \\ ${ }^{8}$ Institute of Mathematical Sciences, University of Malaya, 50603 Kuala Lumpur, Malaysia
}

(Received 27 May 2016; accepted 21 June 2016; published online 15 July 2016)

\begin{abstract}
We present the experimental high-resolution vacuum ultraviolet (VUV) photoabsorption spectra of phenol covering for the first time the full 4.3-10.8 eV energy-range, with absolute cross sections determined. Theoretical calculations on the vertical excitation energies and oscillator strengths were performed using time-dependent density functional theory and the equation-of-motion coupled cluster method restricted to single and double excitations level. These have been used in the assignment of valence and Rydberg transitions of the phenol molecule. The VUV spectrum reveals several new features not previously reported in the literature, with particular reference to the $6.401 \mathrm{eV}$ transition, which is here assigned to the $3 s \sigma / \sigma^{*}(\mathrm{OH}) \leftarrow 3 \pi\left(3 \mathrm{a}^{\prime \prime}\right)$ transition. The measured absolute photoabsorption cross sections have been used to calculate the photolysis lifetime of phenol in the earth's atmosphere (0-50 km). Published by AIP Publishing. [http://dx.doi.org/10.1063/1.4955334]
\end{abstract}

\section{INTRODUCTION}

Phenol, $\mathrm{C}_{6} \mathrm{H}_{5} \mathrm{OH}$, has attracted considerable attention from the international scientific community because of its relevance to industry but it also serves as a model system to biologically related molecules (e.g., amino acids). The conversion of renewable biomass into biofuels has shown to be a non-cooperative procedure (known as being recalcitrant), which still imposes serious cost-ineffective processes in the de-polymerization of biomass into fermentable sugars. ${ }^{1,2}$ Phenol can also be used as a key model for understanding the UV photo-induced dynamics of some amino acids, where $\mathrm{O}-\mathrm{H}$ bond rupture from the phenol moiety can be regarded as a proton release process (or proton tunnelling) from tyrosine residues, which is known to be a prevalent mechanism in a wide range of natural enzymes. ${ }^{3}$ Another key aspect for studying phenol has been centred on probing non-radiative decay processes (from $S_{1}$ to $S_{0}$ ) in aromatic biomolecules, ${ }^{4}$ as well as exploring the role of $\pi \sigma^{*}$ excited states in photodissociation process, allowing therefore to provide distinctively detailed insights into the fragmentation dynamics. ${ }^{5}$ This has been decisive to identify the importance of the strong vibronic

\footnotetext{
${ }^{a)}$ Author to whom correspondence should be addressed. Electronic mail: plimaovieira@fct.unl.pt. Tel.: (+351) 2129478 59. Fax: (+351) 21294 8549.
}

coupling via a conical intersection between the $S_{0}$ and ${ }^{1} \pi \sigma^{*}$ potential energy surfaces at longer $\mathrm{O}-\mathrm{H}$ bond lengths. $^{6-9}$

Phenol, an aromatic hydrocarbon, is considered as an important atmospheric molecule related to urban air pollution as precursor for the formation of photo-oxidants and secondary organic aerosols. The products of the reactions of the photochemical degradation of benzene, toluene, and xyleneisomers with $\mathrm{OH}$ radicals in the terrestrial atmosphere also yield phenol production. ${ }^{10}$ Moreover, the contribution of aromatic hydrocarbons to ozone formation in Europe was estimated to be as high as $40 \%,{ }^{11}$ whilst Etzkorn et al. ${ }^{12}$ have suggested that aromatics are the most important class of hydrocarbons for photochemical ozone formation.

Trost et al. ${ }^{13}$ have reported the room-temperature rate coefficient for reactions of the $\mathrm{OH}$ radical with phenol $\left(k_{\mathrm{OH}}=26.3 \times 10^{-12} \mathrm{~cm}^{3}\right.$ molecule $\mathrm{s}^{-1}$ ), showing that this is likely to be the main sink mechanism for these molecules in the troposphere. Studies on $\mathrm{NO}_{3}$-initiated oxidation of phenol at room temperature have been reported by Atkinson et al. ${ }^{10}$ with a rate constant value of $(2.1 \pm 0.5) \times 10^{-12} \mathrm{~cm}^{3}$ molecules $^{-1}$ $\mathrm{s}^{-1}$, where reactions proceed via $\mathrm{H}$-atom abstraction from the $\mathrm{OH}$ group. Night time reactivity of $\mathrm{NO}_{3}$ radicals with phenol can be regarded as an important sink mechanism for these aromatic hydrocarbons, as well as loss of $\mathrm{NO}_{3}$, possibly contributing as a source of nitric acid, a key component of acid deposition. ${ }^{11,12}$ 
Accurate absorption cross section values, as well as a comprehensive description of the electronic states of aromatic hydrocarbon compounds, are needed as part of a wider research programme aimed at understanding the spectroscopy of these compounds and their role as trace gases in atmospheric chemical and physical reactions. A thorough literature survey reveals scarce data on the vacuum ultraviolet (VUV) electronic state spectroscopy of phenol in a wide energy range as is fully covered in the present contribution. Indeed, experimental information on phenol is mainly restricted to $244<\lambda<283 \mathrm{~nm}(4.38<\mathrm{E}<5.08 \mathrm{eV})^{13}$ and $200<\lambda<290 \mathrm{~nm}(4.28<\mathrm{E}<6.20 \mathrm{eV}),{ }^{14}$ with these studies including no assignments of the absorption bands. Kimura and Nagakura ${ }^{15}$ report the wavelength region $155-300 \mathrm{~nm}$ (4.13-8.00 eV) with four absorption bands assigned to $\pi \leftarrow \pi^{*}$ transitions.

The theoretical data of Lorentzon et al. ${ }^{16}$ cover the energy region (4.53-7.84 eV) with a few assignments of valence states and the first members $(n=3)$ of the Rydberg series converging to the two lowest ionisation energies. Miura and co-workers ${ }^{17}$ have reported oscillator strengths of the $\operatorname{HOMO}(\pi) \rightarrow \operatorname{LUMO}\left(\pi^{*}\right)$ transition through time-dependent density functional theory (TD-DFT), while electron energy-loss spectra have been reported by Ari et al. ${ }^{18}$ Multiphoton ionisation photoelectron spectroscopy of the phenol ${ }^{1} B_{2}$ state has been obtained to provide a consistent set of vibrational assignments, ${ }^{19}$ Kishimoto et $a l .{ }^{20}$ reported on Penning ionisation electron spectra, and Livingstone and co-workers ${ }^{21}$ have performed detailed studies to investigate the dynamical evolution of the initially prepared $S_{1}\left(\pi \pi^{*}\right)$ excited state of phenol through a timeresolved photoelectron imaging technique. The fragmentation dynamics of gas phase phenol following excitation in the wavelength region $279.145 \geq \lambda \geq 260.000 \mathrm{~nm}$ has been investigated by photofragment translational spectroscopy. ${ }^{22}$ Molecular geometries and vibrational spectra of phenol have been reported by experimental and quantum chemical data $^{23}$ as well as by FTIR experiments. ${ }^{24}$ Rotationally resolved fluorescence excitation spectra of the $4.51 \mathrm{eV}$ electronic transition of phenol in a supersonic jet have been measured. ${ }^{25}$ Finally, we note comprehensive experimental and theoretical studies on the excited electronic states of phenol ${ }^{26}$ providing the first investigation of all singlet and triplet states up to the first ionisation potential. This study prefaced substantive electron scattering investigations with phenol ${ }^{27-31}$ that illustrated the important role of phenol's excited and ionised states in describing its scattering behaviour.

Recently we have explored the valence and Rydberg electronic state spectroscopy of a related isoelectronic aromatic hydrocarbon, toluene $\left(\mathrm{C}_{6} \mathrm{H}_{5} \mathrm{CH}_{3}\right){ }^{32}$ relevant to urban pollution, where fossil fuel, industrial burning, and biomass burning are the common sources of emissions. Thorough knowledge gained on the spectroscopic nature of toluene assists in the assignment of the absorption bands of phenol.

In this paper, we report the results of an extensive study of the electronic state spectroscopy of phenol by high resolution VUV photoabsorption spectroscopy and $a b$ initio theoretical calculations of the vertical excitation energies and oscillator strengths for the neutral electronic transitions. In Sec. II, we provide a brief summary of the structure and properties of phenol. In addition to identifying the optical electronic transitions of phenol, the present work provides reliable photoabsorption cross sections in the range 4.3-10.8 eV. In Section III, we present the computational methods and in Section IV a brief discussion of the experimental details. Section $\mathrm{V}$ is devoted to the results and discussion with a comparison with other absolute photoabsorption cross sections. The absolute photoabsorption cross sections are used to calculate photolysis rates in the earth's atmosphere up to the limit of the stratopause $(50 \mathrm{~km})$. Finally some conclusions that can be drawn from this study are given in Section VI.

\section{BRIEF SUMMARY OF THE STRUCTURE AND PROPERTIES OF PHENOL}

Phenol has symmetry $C_{\mathrm{S}}$ in the electronic ground state, and the symmetry species available are $\mathrm{A}^{\prime}$ and $\mathrm{A}^{\prime \prime}$. The calculated electron configuration of the $\tilde{X}^{1} \mathrm{~A}^{\prime}$ ground state according to Jones et al. ${ }^{26}$ is (a) core orbitals $\left(1 \mathrm{a}^{\prime}\right)^{2}\left(2 \mathrm{a}^{\prime}\right)^{2}\left(3 \mathrm{a}^{\prime}\right)^{2}$ $\left(4 a^{\prime}\right)^{2}\left(5 a^{\prime}\right)^{2}\left(6 a^{\prime}\right)^{2}\left(7 a^{\prime}\right)^{2}$ and (b) valence orbitals $\left(8 a^{\prime}\right)^{2}\left(9 a^{\prime}\right)^{2}$ $\left(10 a^{\prime}\right)^{2}\left(11 a^{\prime}\right)^{2}\left(12 a^{\prime}\right)^{2}\left(13 a^{\prime}\right)^{2}\left(14 a^{\prime}\right)^{2}\left(15 a^{\prime}\right)^{2}\left(16 a^{\prime}\right)^{2}\left(17 a^{\prime}\right)^{2}$ $\left(18 a^{\prime}\right)^{2}\left(1 a^{\prime \prime}\right)^{2}\left(19 a^{\prime}\right)^{2}\left(20 a^{\prime}\right)^{2}\left(21 a^{\prime}\right)^{2}\left(2 a^{\prime \prime}\right)^{2}\left(3 a^{\prime \prime}\right)^{2}\left(4 a^{\prime \prime}\right)^{2}$. The highest occupied molecular orbital (HOMO) $4 a^{\prime \prime}$, the second highest occupied molecular orbital (HOMO-1) 3a", and the third highest occupied molecular orbital (HOMO-2) $2 a^{\prime \prime}$ have $\pi$ character and may be labelled $4 \pi, 3 \pi$, and $2 \pi$, respectively. The lowest unoccupied molecular orbitals (LUMOs) $5 \mathrm{a}^{\prime \prime}$ and (LUMO+1) 6a" are mainly of $\pi^{*}$ antibonding character, with $(\mathrm{LUMO}+1)$ having a slight $\sigma^{*}$ character along the $\mathrm{C}-\mathrm{OH}$ bond. Note that the $3 \mathrm{~s} / \sigma^{*}(\mathrm{OH})$ is labelled $(\mathrm{LUMO}+1)$ in Ref. 26, whereas here the LUMO notation is reserved to pure valence MOs. Thus (LUMO+2) in Jones et al. ${ }^{26}$ is now labelled $(\mathrm{LUMO}+1)$.

The earlier studies of Lorentzon et al. ${ }^{16}$ have predicted at the CASPT2 (complete active space self-consistent field with second-order perturbation correction) level of theory the valence and $3 s, 3 p$, and $3 d$ Rydberg states whereas the recent experimental data on the electron-energy loss spectroscopy, ${ }^{26}$ at moderate electron energy resolution $(\Delta E \sim 70 \mathrm{meV})$, did not allow for a more quantitative assignment of the Rydberglike transitions. Bearing in mind the resemblance between phenol and toluene photoabsorption spectra, we may anticipate for the former an overlap of Rydberg states with valence states resulting in a complex intensity distribution in the electronic spectrum. Rydberg states may be identified through knowledge of the ionisation energies and the application of quantum defect theory. The three lowest ionisation energies, which are required to calculate the quantum defects associated with transitions to Rydberg orbitals, have been identified experimentally to be at $8.64,9.32$, and $11.57 \mathrm{eV}^{20}$

\section{COMPUTATIONAL DETAILS}

Electronic structure calculations were performed with two different methods (TD-DFT and equation-of-motion coupled cluster method restricted to single and double excitations (EOM-CCSD)) to determine the excitation energies of the 
TABLE I. Calculated vertical excitation energies (TD-DFT level at the LC- $\omega$ PBE/aug-cc-pVTZ $+\mathrm{R})(\mathrm{eV})$, optical oscillator strengths $\left(f_{\mathrm{L}}\right)$, assignments, and dominant configurations of phenol $\left(\mathrm{C}_{6} \mathrm{H}_{5} \mathrm{OH}\right)$ compared with experimental data and other work (details in text).

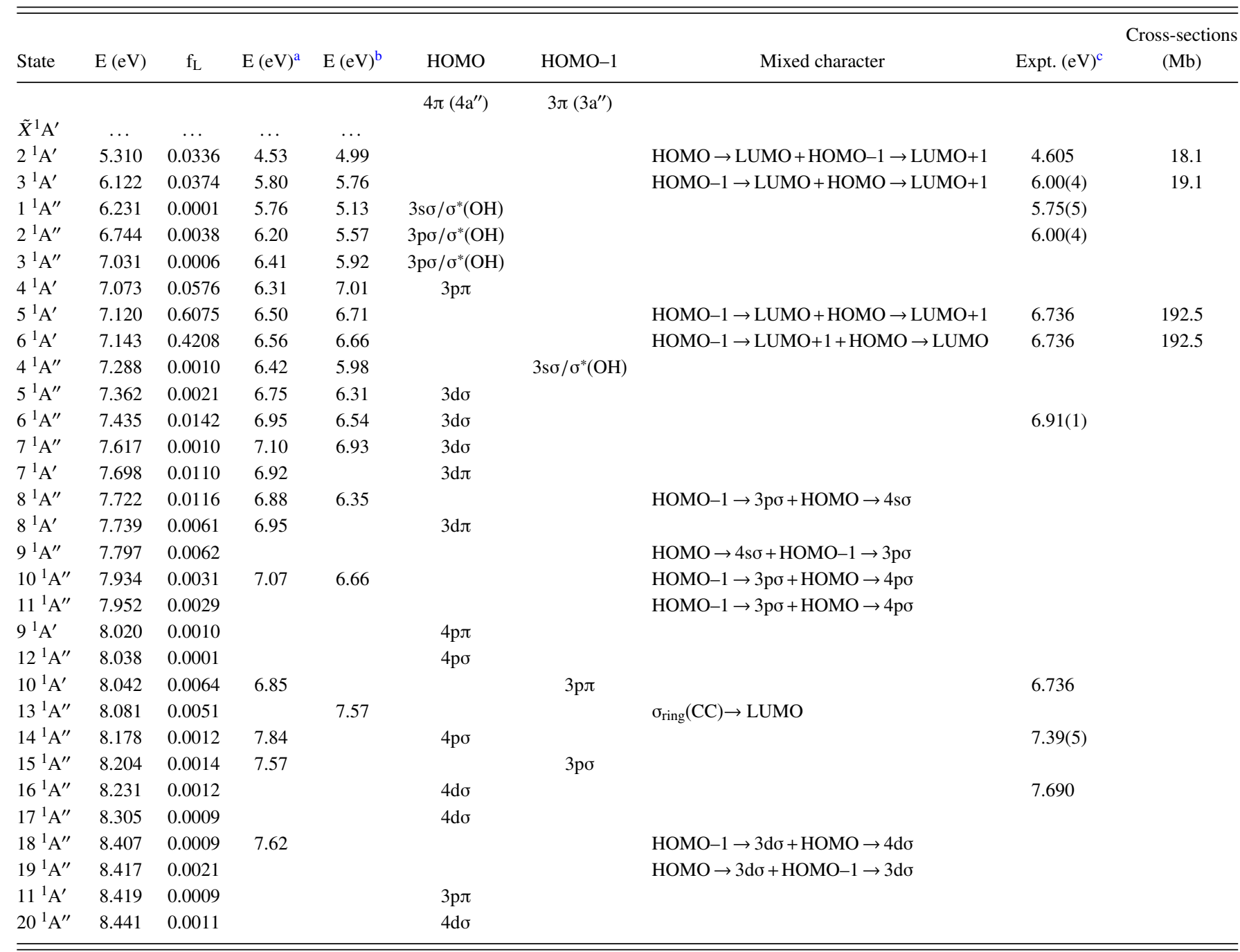

${ }^{\mathrm{a}}$ Reference 16 (CASPT2/ANO+R)

${ }^{\mathrm{b}}$ Reference 26 (TD-DFT B3LYP/aug-cc-pVDZ).

${ }^{\mathrm{c}}$ The last decimal of the energy value is given in brackets for these less-resolved features.

neutral molecules (Tables I and II) and the lowest ionisation energy. Density Functional Theory (DFT) using the LC- $\omega$ PBE long range corrected functional ${ }^{33-35}$ has been implemented with the Gaussian 09 code. $^{36}$ The geometry (Fig. 1) and harmonic frequencies were obtained using Dunning's cc-pVTZ basis set. ${ }^{37}$ Then the properties of the excited states (energies and oscillator strengths in the length gauge) were obtained using TD-DFT for both triplet and singlet states. The basis set was augmented to aug-cc-pVTZ for all atoms and a set of diffuse (5s5p2d) orbitals, taken from Kaufmann et al. ${ }^{38}$ was added to the centre of the benzenic ring (aug-cc-pVTZ+R basis set). The nature of the transitions was assessed by visual inspection of the natural transition orbitals (NTOs), ${ }^{39}$ computed for each calculated triplet and singlet transition.

Phenol geometry was also obtained at the $\operatorname{CCSD}(\mathrm{T})$ level with the Molpro 2012.1 code $^{40}$ with the cc-pVTZ basis set (Fig. 1). The lowest lying singlet transitions were then calculated at the EOM-CCSD (equation-of-motion coupled cluster method restricted to single and double excitations) level, using the aug-cc-pVTZ+R basis set. The nature of each transition was assessed by visual inspection of the corresponding EOM-CCSD natural orbitals for each transition. Finally, the lowest vertical ionization energy was also obtained at the $\operatorname{RCCSD}(\mathrm{T})$ level. ${ }^{39}$

\section{EXPERIMENTAL DETAILS}

\section{A. Phenol sample}

The liquid sample used in the VUV measurements was purchased from Sigma-Aldrich, with a stated purity of $\geq 99.5 \%$. The sample was degassed by repeated freeze-pump-thaw cycles.

\section{B. VUV photoasorption}

The high-resolution VUV absorption spectrum of phenol (Fig. 2) was measured at the ASTRID2 storage ring at Aarhus University, Denmark, using the AU-UV beam line. 
TABLE II. Calculated vertical excitation energies (EOM-CCSD level at the aug-cc-pVTZ+R basis set) (eV), optical oscillator strengths ( $\left.f_{\mathrm{L}}\right)$, assignments, and dominant configurations $\left(\mathrm{C}_{6} \mathrm{H}_{5} \mathrm{OH}\right)$ compared with experimental data and other work (details in text).

\begin{tabular}{|c|c|c|c|c|c|c|c|c|c|c|c|}
\hline State & $E(e V)$ & $\mathrm{f}_{\mathrm{L}}$ & $\left\langle r^{2}\right\rangle^{\mathrm{a}}$ & $\mathrm{E}(\mathrm{eV})^{\mathrm{b}}$ & $\mathrm{E}(\mathrm{eV})^{\mathrm{c}}$ & HOMO & HOMO-1 & HOMO-2 & Mixed character & Expt. $(e V)^{d}$ & $\begin{array}{c}\text { Cross-sections } \\
\text { (Mb) }\end{array}$ \\
\hline & & & & & & $4 \pi\left(4 a^{\prime \prime}\right)$ & $3 \pi\left(3 a^{\prime \prime}\right)$ & $2 \pi\left(2 a^{\prime \prime}\right)$ & & & \\
\hline$\tilde{X}^{1} \mathrm{~A}^{\prime}$ & $\ldots$ & $\ldots$ & 88 & & & & & & & & \\
\hline $2{ }^{1} \mathrm{~A}^{\prime}$ & 4.947 & 0.0210 & 91 & 4.53 & 4.99 & $\operatorname{LUMO}\left(5 \mathrm{a}^{\prime \prime}, 1 \pi^{*}\right)$ & & & & 4.605 & 18.1 \\
\hline $1{ }^{1} \mathrm{~A}^{\prime \prime}$ & 5.699 & 0.0002 & 108 & 5.76 & 5.13 & $3 \mathrm{~s} \sigma / \sigma^{*}(\mathrm{OH})$ & & & & $5.75(5)$ & \\
\hline $3{ }^{1} \mathrm{~A}^{\prime}$ & 6.162 & 0.0337 & 99 & 5.80 & 5.76 & LUMO+1 $\left(6 a^{\prime \prime}, 2 \pi^{*}\right)$ & & & & $6.00(4)$ & 19.1 \\
\hline $2{ }^{1} \mathrm{~A}^{\prime \prime}$ & 6.184 & 0.0043 & 168 & 6.20 & 5.57 & $3 \mathrm{p} \sigma / \sigma^{*}(\mathrm{OH})$ & & & & $6.00(4)$ & \\
\hline $3{ }^{1} \mathrm{~A}^{\prime \prime}$ & 6.491 & 0.0004 & 160 & 6.41 & 5.92 & $3 \mathrm{p} \sigma$ & & & & & \\
\hline $4{ }^{1} \mathrm{~A}^{\prime \prime}$ & 6.634 & 0.0011 & 138 & 6.42 & 5.98 & & $3 \mathrm{~s} \sigma / \sigma^{*}(\mathrm{OH})$ & & & $5.89(3) / 6.401$ & \\
\hline $4{ }^{1} \mathrm{~A}^{\prime}$ & 6.642 & 0.0183 & 161 & 6.31 & 7.01 & $3 \mathrm{p} \pi$ & & & & & \\
\hline $5{ }^{1} \mathrm{~A}^{\prime \prime}$ & 6.876 & 0.0053 & 181 & 6.75 & 6.31 & $3 \mathrm{~d} \sigma$ & & & & & \\
\hline $6{ }^{1} \mathrm{~A}^{\prime \prime}$ & 6.906 & 0.0089 & 178 & 6.95 & 6.54 & $3 \mathrm{~d} \sigma$ & & & & $6.91(1)$ & \\
\hline $5{ }^{1} \mathrm{~A}^{\prime}$ & 7.011 & 0.3889 & 113 & 6.50 & 6.66 & & & & $\begin{array}{l}\mathrm{HOMO} \rightarrow \text { LUMO } \\
+\mathrm{HOMO}-1 \rightarrow \mathrm{LUMO}+1\end{array}$ & 6.736 & 192.5 \\
\hline $7{ }^{1} \mathrm{~A}^{\prime \prime}$ & 7.079 & 0.0117 & 153 & 6.88 & 6.35 & & $3 p \sigma$ & & & & \\
\hline $6{ }^{1} \mathrm{~A}^{\prime}$ & 7.101 & 0.5172 & 123 & 6.56 & 6.71 & & & & $\begin{array}{l}\text { HOMO }-1 \rightarrow \text { LUMO } \\
+\mathrm{HOMO} \rightarrow 3 \mathrm{~d} \pi\end{array}$ & 6.736 & 192.5 \\
\hline $8{ }^{1} \mathrm{~A}^{\prime \prime}$ & 7.113 & 0.0001 & 194 & 7.10 & 6.93 & $3 \mathrm{~d} \sigma$ & & & & & \\
\hline $9{ }^{1} \mathrm{~A}^{\prime \prime}$ & 7.276 & 0.0130 & 164 & 7.07 & 6.66 & & $3 p \sigma$ & & & & \\
\hline $7{ }^{1} \mathrm{~A}^{\prime}$ & 7.280 & 0.0840 & 202 & 6.92 & & $3 \mathrm{~d} \pi$ & & & & & \\
\hline $10^{1} \mathrm{~A}^{\prime \prime}$ & 7.325 & $<0.0001$ & 298 & & & $4 \mathrm{~s} \sigma$ & & & & $7.12(8)$ & \\
\hline $8{ }^{1} \mathrm{~A}^{\prime}$ & 7.337 & 0.1376 & 192 & 6.95 & & $3 \mathrm{~d} \pi$ & & & & & \\
\hline $11^{1} \mathrm{~A}^{\prime \prime}$ & 7.494 & 0.0012 & 425 & & & $4 \mathrm{p} \sigma$ & & & & $7.39(5)$ & \\
\hline $9{ }^{1} \mathrm{~A}^{\prime}$ & 7.555 & 0.0603 & 178 & 6.85 & & & $3 p \pi$ & & & 6.736 & \\
\hline $12{ }^{1} \mathrm{~A}^{\prime \prime}$ & 7.581 & 0.0002 & 436 & & & $4 \mathrm{p} \sigma$ & & & & & \\
\hline $10{ }^{1} \mathrm{~A}^{\prime}$ & 7.592 & 0.0069 & 434 & & & $4 \mathrm{p} \pi$ & & & & & \\
\hline $13{ }^{1} \mathrm{~A}^{\prime \prime}$ & 7.654 & 0.0007 & 163 & 7.57 & 7.08 & & $3 \mathrm{~d} \sigma$ & & & & \\
\hline $14{ }^{1} \mathrm{~A}^{\prime \prime}$ & 7.732 & 0.0002 & 272 & 7.62 & & & & & $\begin{array}{l}\mathrm{HOMO}-1 \rightarrow 3 \mathrm{~d} \sigma \\
+\mathrm{HOMO} \rightarrow 4 \mathrm{~d} \sigma\end{array}$ & & \\
\hline $15^{1} \mathrm{~A}^{\prime \prime}$ & 7.758 & 0.0004 & 261 & 7.84 & & & & & $\begin{array}{l}\mathrm{HOMO} \rightarrow 4 \mathrm{~d} \sigma \\
+\mathrm{HOMO}-1 \rightarrow 3 \mathrm{~d} \sigma\end{array}$ & & \\
\hline $16{ }^{1} \mathrm{~A}^{\prime \prime}$ & 7.798 & 0.0016 & 426 & & & $4 \mathrm{~d} \sigma$ & & & & 7.690 & \\
\hline $17^{1} \mathrm{~A}^{\prime \prime}$ & 7.836 & 0.0016 & 312 & & & $4 \mathrm{~d} \sigma^{\mathrm{e}}$ & & & & 7.690 & \\
\hline $18^{1} \mathrm{~A}^{\prime \prime}$ & 7.879 & 0.0002 & 675 & & & $5 \mathrm{~s} \sigma$ & & & & 7.802 & \\
\hline $19^{1} \mathrm{~A}^{\prime \prime}$ & 7.903 & 0.0002 & 362 & & & $4 \mathrm{~d} \sigma$ & & & & & \\
\hline $20{ }^{1} \mathrm{~A}^{\prime \prime}$ & 7.972 & 0.0001 & 243 & & & & $3 \mathrm{~d} \sigma$ & & & & \\
\hline $21^{1} \mathrm{~A}^{\prime \prime}$ & 7.989 & 0.0022 & 818 & & & $5 \mathrm{p} \sigma$ & & & & 7.885 & \\
\hline $11^{1} \mathrm{~A}^{\prime}$ & 7.992 & 0.0027 & 974 & & & $4 \mathrm{~d} \pi$ & & & & & \\
\hline $22{ }^{1} \mathrm{~A}^{\prime \prime}$ & 8.007 & 0.0009 & 1013 & & & $5 \mathrm{p} \sigma$ & & & & & \\
\hline $23{ }^{1} \mathrm{~A}^{\prime \prime}$ & 8.023 & 0.0018 & 443 & & & $5 \mathrm{~d} \sigma$ & & & & & \\
\hline $12{ }^{1} \mathrm{~A}^{\prime}$ & 8.043 & 0.0040 & 210 & & & & $3 \mathrm{~d} \pi$ & & & & \\
\hline $13^{1} \mathrm{~A}^{\prime}$ & 8.069 & 0.0093 & 369 & & & & $3 \mathrm{~d} \pi$ & & & 7.562 & \\
\hline $14{ }^{1} \mathrm{~A}^{\prime}$ & 8.120 & 0.0024 & 304 & & & $5 \mathrm{~d} \pi$ & & & & & \\
\hline $24{ }^{1} \mathrm{~A}^{\prime \prime}$ & 8.124 & 0.0059 & 865 & & & $5 \mathrm{~d} \sigma$ & & & & 8.040 & \\
\hline $15^{1} \mathrm{~A}^{\prime}$ & 8.146 & 0.0046 & 206 & & & $5 \mathrm{~d} \pi$ & & & & & \\
\hline $25^{1} \mathrm{~A}^{\prime \prime}$ & 8.165 & 0.0046 & 1046 & & & $5 \mathrm{~d} \sigma$ & & & & & \\
\hline $26^{1} \mathrm{~A}^{\prime \prime}$ & 8.170 & 0.0002 & 355 & & & & $4 \mathrm{~s} \sigma$ & & & 7.803 & \\
\hline $27^{1} \mathrm{~A}^{\prime \prime}$ & 8.228 & 0.0052 & 104 & & 7.57 & & & & $\sigma_{\text {ring }} \rightarrow$ LUMO & & \\
\hline $28{ }^{1} \mathrm{~A}^{\prime \prime}$ & 8.246 & 0.0010 & 208 & & & $5 \mathrm{~d} \sigma$ & & & & & \\
\hline $29^{1} \mathrm{~A}^{\prime \prime}$ & 8.281 & 0.0005 & 1005 & & & $5 \mathrm{p} \sigma$ & & & & & \\
\hline $16{ }^{1} \mathrm{~A}^{\prime}$ & 8.344 & 0.0007 & 978 & & & $5 p \pi$ & & & & & \\
\hline $30^{1} \mathrm{~A}^{\prime \prime}$ & 8.347 & 0.0018 & 433 & & & & $4 \mathrm{po}$ & & & & \\
\hline $17^{1} \mathrm{~A}^{\prime}$ & 8.420 & 0.0007 & 442 & & & & $4 \mathrm{p} \pi$ & & & 8.072 & \\
\hline
\end{tabular}


TABLE II. (Continued.)

\begin{tabular}{|c|c|c|c|c|c|c|c|c|c|c|c|}
\hline State & $E(e V)$ & $f_{L}$ & $\left\langle r^{2}\right\rangle^{\mathrm{a}}$ & $\mathrm{E}(\mathrm{eV})^{\mathrm{b}}$ & $\mathrm{E}(\mathrm{eV})^{\mathrm{c}}$ & HOMO & HOMO-1 & HOMO-2 & Mixed character & Expt. $(e V)^{\mathrm{d}}$ & $\begin{array}{c}\text { Cross-sections } \\
(\mathrm{Mb})\end{array}$ \\
\hline $18^{1} \mathrm{~A}^{\prime}$ & 8.712 & 0.0745 & 167 & & & & & $\begin{array}{l}\text { LUMO } \\
\left(5 \mathrm{a}^{\prime \prime}, 1 \pi\right)\end{array}$ & & & \\
\hline $19^{1} \mathrm{~A}^{\prime}$ & 8.829 & 0.0036 & 872 & & & & $4 \mathrm{~d} \pi$ & & & 8.400 & \\
\hline $20{ }^{1} \mathrm{~A}^{\prime}$ & 8.858 & 0.0003 & 372 & & & & $4 \mathrm{~d} \pi$ & & & & \\
\hline
\end{tabular}

${ }^{\mathrm{a}}$ Mean value of $\mathrm{r}^{2}$ (electronic radial spatial extents).

${ }^{\mathrm{b}}$ Reference 16 (CASPT2/ANO+R).

${ }^{\mathrm{c}}$ Reference 26 (TD-DFT B3LYP/aug-cc-pVDZ).

${ }^{\mathrm{d}}$ The last decimal of the energy value is given in brackets for these less-resolved features.

${ }^{\mathrm{e}}$ This MO has a f-shape character as in the $\sigma^{*}(\mathrm{CC}) \mathrm{MO}$ of cyclopropane, see discussion in Refs. 52 and 53.

The apparatus used for measurement of photoabsorption spectra has undergone several alterations since that originally described in the work of Eden et al. ${ }^{41}$ with those modifications being described recently in Ref. 42. Briefly, the gas cell,

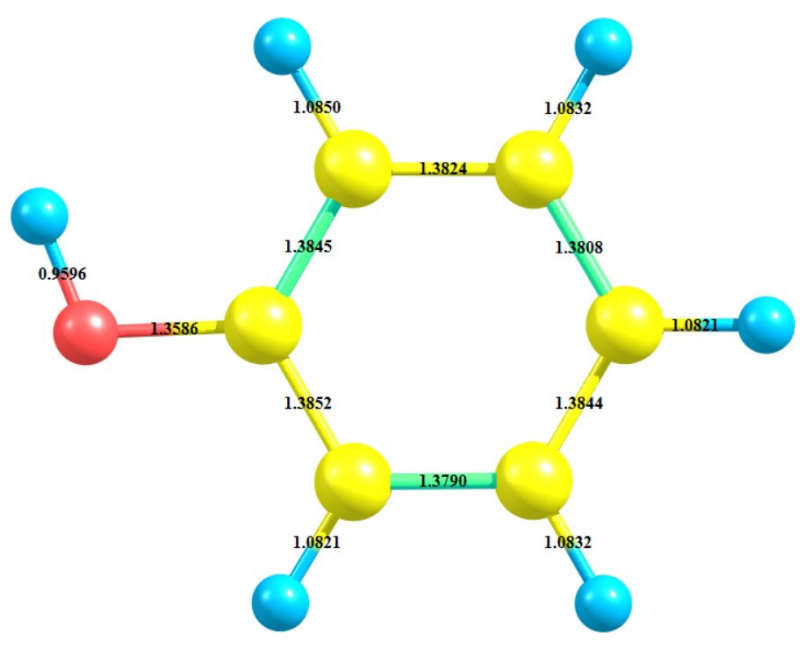

(a)

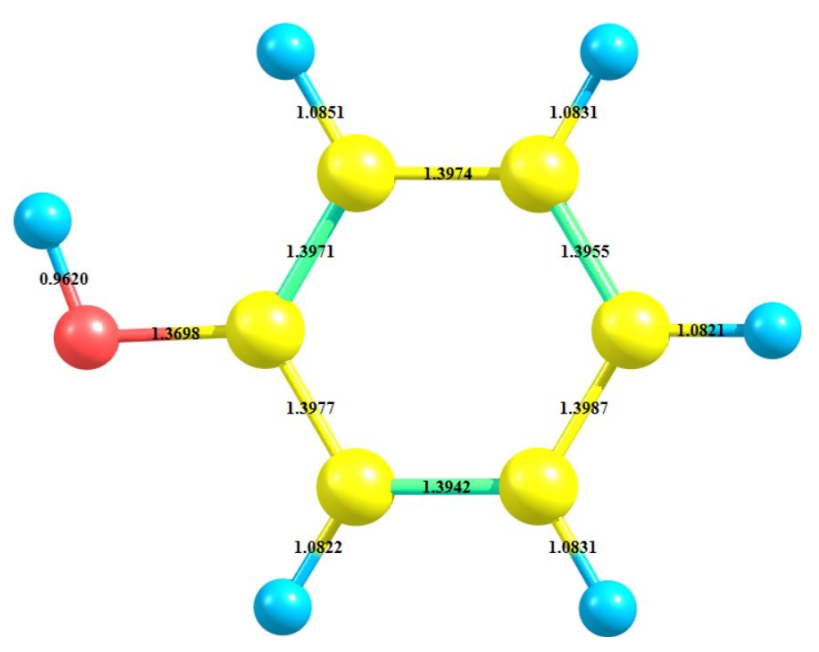

(b)

FIG. 1. Calculated structure of phenol, $\mathrm{C}_{6} \mathrm{H}_{5} \mathrm{OH}$, optimized at (a) LC$\omega \mathrm{PBE} / \mathrm{cc}-\mathrm{pVTZ}$ geometry and (b) CCSD(T)/cc-pVTZ geometry. Distances in $\AA$. which allows moderate (up to $80^{\circ} \mathrm{C}$ ) heating of a sample during measurement, has a path length of $15.5 \mathrm{~cm}$ and is fitted with a heated 1 Torr Baratron capacitance manometer (Setra model 774). To ensure that the data are free of any saturation effects, the absorption cross sections were measured at an appropriate pressure in the range $0.02-0.43 \mathrm{mbar}$, with typical attenuations of less than $40 \%$. The light exits the cell through a $\mathrm{MgF}_{2}$ window, which sets the lower limit of detectable light to $115 \mathrm{~nm}$. A small gap between the photo-multiplier tube (PMT) detector and the absorption cell is evacuated using a scroll pump for measurements below $200 \mathrm{~nm}$. Above $220 \mathrm{~nm}$, air is allowed into this gap to let oxygen absorb higher orders of light (at half the chosen wavelength) which may be passing through the cell. In this way, photoabsorption measurements can be performed with spectrally pure radiation from $115 \mathrm{~nm}$ to $340 \mathrm{~nm}$, ensuring artefact-free spectra. Absolute photoabsorption cross sections $(\sigma)$ are obtained using the Beer-Lambert law $I_{t}=I_{0} \exp (-n \sigma x)$, where $I_{t}$ is the radiation intensity transmitted through the gas sample, $I_{0}$ is that through the evacuated cell, $n$ is the molecular number density of the sample gas, $\sigma$ is the absolute photoabsorption cross section, and $x$ is the absorption path length $(15.5 \mathrm{~cm})$. ASTRID2 is operated in a so-called top-up mode, keeping the stored electron beam current (and thus the intensity for a given wavelength) quasi-constant by adding small amounts of current to ASTRID2 to make up for the constant beam decay.

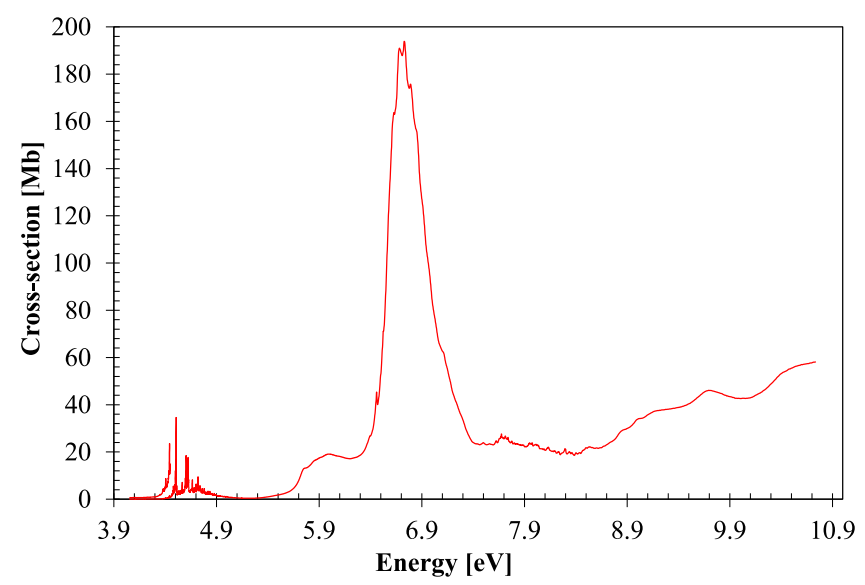

FIG. 2. High resolution VUV photoabsorption spectrum of phenol, $\mathrm{C}_{6} \mathrm{H}_{5} \mathrm{OH}$, in the $3.9-10.8 \mathrm{eV}$ photon energy range. 
The beam current thus varies about 3\% during a scan, and this is taken into account by recording and normalizing to an accurately determined beam current.

The accuracy of the cross section is estimated to be better than $\pm 5 \%$. Only when absorption by the sample is very weak $\left(I_{0} \approx I_{t}\right)$, does the error increase as a percentage of the measured cross section.

\section{ELECTRONIC STATE SPECTROSCOPY: RESULTS AND DISCUSSION}

The absolute high resolution VUV photoabsorption spectrum of phenol measured at room temperature is shown in Fig. 2, extending from 3.9 to $10.8 \mathrm{eV}$ and Figs. 3-7 show expanded views in five subsection energy regions. The major absorption bands can be classified as a mixture of Rydberg series and molecular valence transitions of $\left(\pi^{*} \leftarrow \pi\right)$ character. Table I compares the experimental results with the TD-DFT calculations and demonstrates reasonably good agreement. The calculations indicate that the electronic transitions for phenol have mixed valence-Rydberg character. The RCCSD(T) lowest vertical ionisation energy is $8.60 \mathrm{eV}$ (Table II) and agrees well with Lorentzon et al. ${ }^{16}$ (8.21 and $8.56 \mathrm{eV})$ and Kishimoto et $a .^{20}(8.64 \mathrm{eV})$. The measured lowest vertical IE of phenol $(8.64 \mathrm{eV})^{20}$ agrees well with the theoretical prediction. ${ }^{16}$ There exists several different numbering schemes of the vibrational modes of phenol in the literature, and we have followed the notation adopted in the studies of Anderson et al. ${ }^{19}$ and $\mathrm{Nix}$ et $a .^{22}$ in Secs. V A-V B.

\section{A. Valence spectroscopy of phenol}

According to the calculation results in Tables I and II, the absorption bands centred at 4.605, 6.00(4), and $6.736 \mathrm{eV}$ have been assigned to $\left(\pi^{*} \leftarrow \pi\right)$ transitions. The calculated wave functions show a mixing between excitations from the HOMO $(4 \pi)$ and HOMO-1 $(3 \pi)$ to the LUMO $\left(\pi^{*}\right)$ and LUMO+1 $\left(\pi^{*}\right)$ MO's, and also a 3s $\sigma\left(a^{\prime \prime}\right)$ Rydberg character for the latter. An identical behaviour has been observed for toluene. ${ }^{27}$

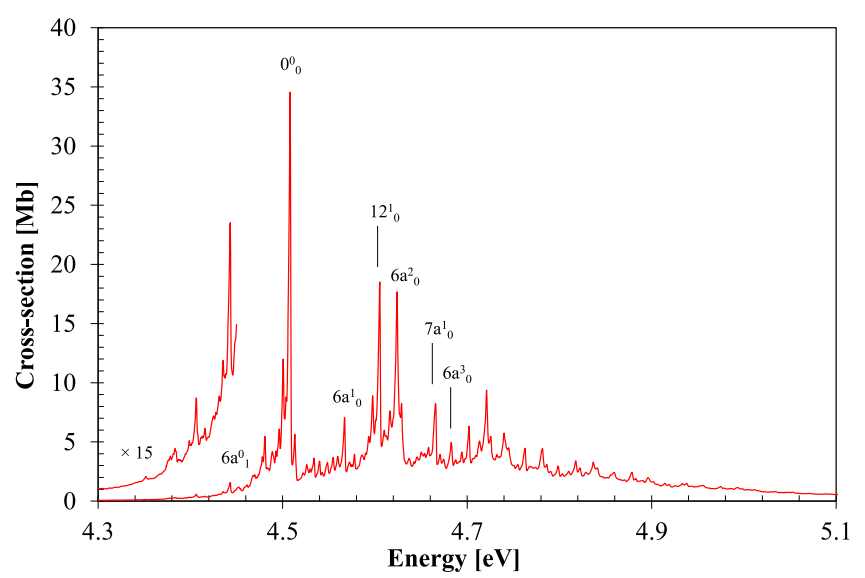

FIG. 3. High resolution VUV photoabsorption spectrum of phenol, $\mathrm{C}_{6} \mathrm{H}_{5} \mathrm{OH}$, in the 4.3-5.1 eV photon energy range. For the vibrational excitation assignments, see Table III and text for details.

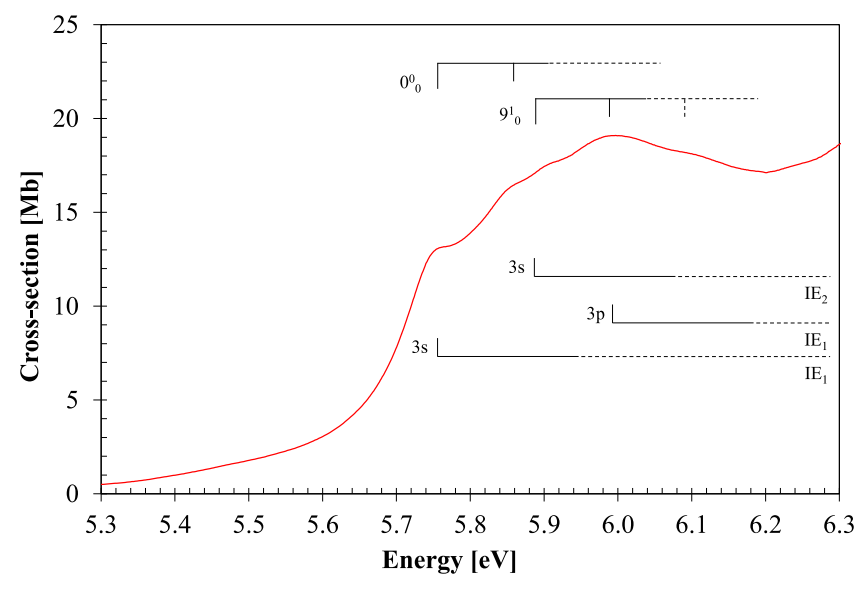

FIG. 4. High resolution VUV photoabsorption spectrum of phenol, $\mathrm{C}_{6} \mathrm{H}_{5} \mathrm{OH}$, in the 5.3-6.3 eV photon energy range. For the vibrational excitation and Rydberg state assignments, see Tables IV and VI and text for details.

The calculated transition energies at the EOM-CCSD level (Table II) are generally overestimated by about $0.3 \mathrm{eV}$ when compared to experiment, whereas for TD-DFT level of theory (Table I) such a difference increases on average to $0.5 \mathrm{eV}$. Thus, in this case the EOM-CCSD results are more reliable than the TD-DFT ones, especially for Rydberg transitions. Nevertheless, the present TD-DFT/LC- $\omega$ PBE/aug-cc-pVTZ+R calculations appear to be closer to other theoretical results than the TD-DFT/B3LYP/aug-cc-pVDZ of Ref. 26. The assignments in the lowest absorption band are in a reasonable agreement with the work of Nix et al., ${ }^{22}$ reporting the band at $4.507 \mathrm{eV}(275.113 \mathrm{~nm})$, while electron energy loss data of Ari et $a l .{ }^{18}$ place the first three bands at $4.59,5.93$, and $6.68 \mathrm{eV}$, respectively, and that of Kimura and Nagakura ${ }^{15}$ at 4.59, 5.82, and $6.70 \mathrm{eV}$.

The first band is reported here with a maximum absolute cross section of $18.1 \mathrm{Mb}$ (at $4.605 \mathrm{eV}$ ), whereas the second has a maximum of $19.1 \mathrm{Mb}$ (at $6.00(4) \mathrm{eV}$ ) and the third at $192.5 \mathrm{Mb}$ (at $6.736 \mathrm{eV}$ ) (see Tables I and II). The feature at $6.401 \mathrm{eV}$, with a rather weak calculated oscillator strength, $\mathrm{f}_{\mathrm{L}} \approx 0.001$, is here tentatively assigned for the first time to $\sigma^{*}(\mathrm{OH}) \leftarrow 3 \pi\left(3 \mathrm{a}^{\prime \prime}\right)$ with the aid of the theoretical

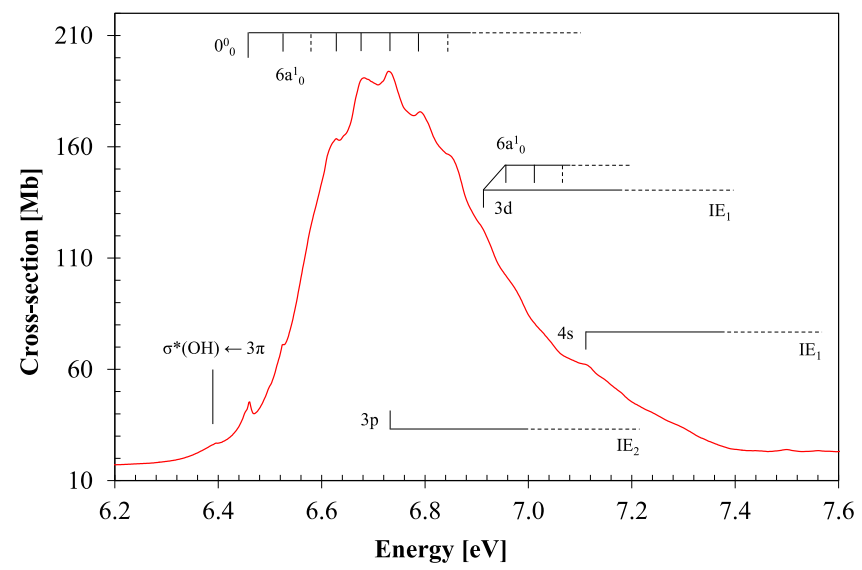

FIG. 5. High resolution VUV photoabsorption spectrum of phenol, $\mathrm{C}_{6} \mathrm{H}_{5} \mathrm{OH}$, in the $6.2-7.6 \mathrm{eV}$ photon energy range. For the vibrational excitation and Rydberg state assignments, see Tables V and VI and text for details. 


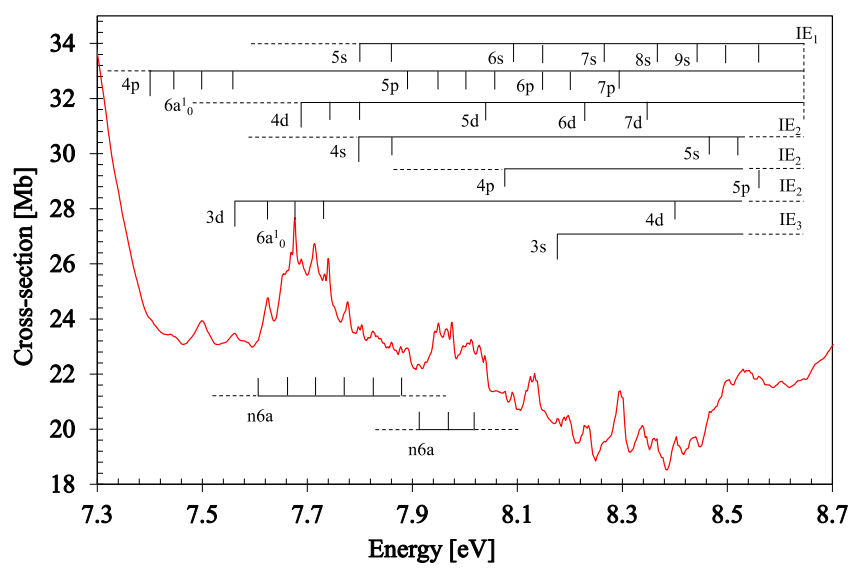

FIG. 6. High resolution VUV photoabsorption spectrum of phenol, $\mathrm{C}_{6} \mathrm{H}_{5} \mathrm{OH}$, in the 7.3-8.7 eV photon energy range. For the vibrational excitation and Rydberg state assignments, see Tables V and VI and text for details.

calculations (Table II). However, a careful look at Table II reveals that for this energy transition, other contributions from $3 \mathrm{p} \sigma / \sigma^{*}(\mathrm{OH}) \leftarrow 4 \pi$ and $3 \mathrm{~s} \sigma / \sigma^{*}(\mathrm{OH}) \leftarrow 3 \pi$ may be present. The feature at $6.736 \mathrm{eV}$ has been identified as an $\mathrm{n}=3 \mathrm{p}$ member of a Rydberg series converging to the ionic electronic first excited state of phenol (see Section V B); the rather high calculated intensity $\left(\mathrm{f}_{\mathrm{L}} \approx 0.060\right.$ in Table II) is primarily due to the pure valence $\pi^{*}$ character of the MO. Pure Rydberg transitions (Table VI) with considerable values of oscillator strengths in this energy range are discussed in Sec. V B.

\section{Valence and vibronic excitation in the range 4.4-5.5 eV}

The lowest-lying excited state of phenol $\left(2 \pi^{*} \leftarrow 3 \pi\right.$ $+1 \pi^{*} \leftarrow 4 \pi$ ), with a maximum at $4.605 \mathrm{eV}$, with a local cross section value of $18.1 \mathrm{Mb}$ (Fig. 3), has been assigned to the $S_{1}-S_{0}\left(\pi^{*} \leftarrow \pi\right)$ transition and shows extensive fine structure, which is much better resolved than in previous absolute cross section measurements ${ }^{22}$ and therefore new assignments are proposed. The vertical energy is in good agreement with the calculated value of $4.99 \mathrm{eV}$ of Jones et al. ${ }^{26}$ as well as from the present calculations in Tables I and II, where the

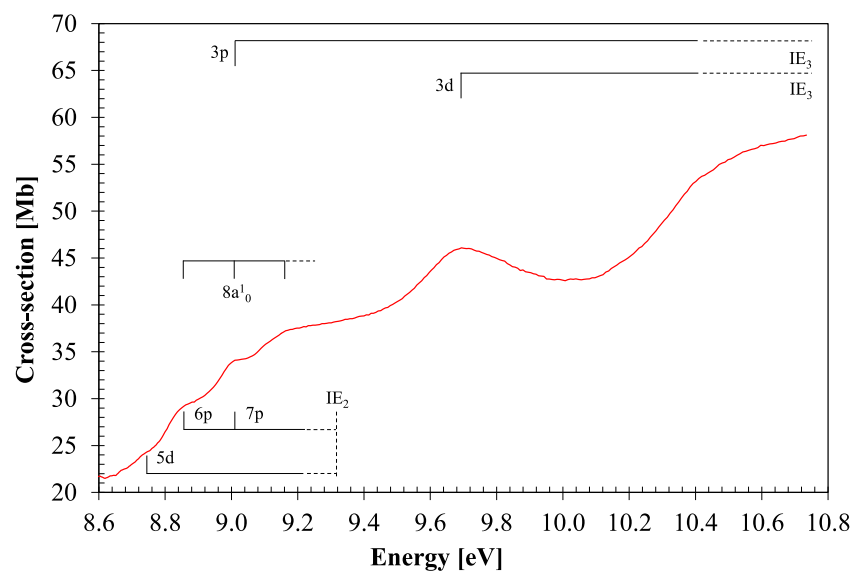

FIG. 7. High resolution VUV photoabsorption spectrum of phenol, $\mathrm{C}_{6} \mathrm{H}_{5} \mathrm{OH}$, in the $8.6-10.8 \mathrm{eV}$ photon energy range with Rydberg and vibrational excitation assignments. See Tables V and VI and text for details.
TABLE III. Proposed vibrational assignments in the 4.3-5.1 eV absorption band of phenol, $\mathrm{C}_{6} \mathrm{H}_{5} \mathrm{OH}{ }^{\mathrm{a}}$

\begin{tabular}{|c|c|c|c|}
\hline Energy $(\mathrm{eV})$ & Assignment & Energy $(\mathrm{eV})$ & Assignment \\
\hline \multicolumn{2}{|c|}{ This work $^{\mathrm{b}}$} & \multicolumn{2}{|c|}{ Nix et al..$^{22}$} \\
\hline 4.355 & $7 a_{1}^{0}$ & $\ldots$ & $\ldots$ \\
\hline 4.380 & $18_{1}^{0}$ & $\ldots$ & $\ldots$ \\
\hline 4.383 & $6 a_{2}^{0}$ & $\ldots$ & $\ldots$ \\
\hline 4.406 & $12_{1}^{2}$ & $\ldots$ & $\ldots$ \\
\hline 4.416 & $18 b_{2}^{0}$ & $\ldots$ & $\ldots$ \\
\hline 4.440 & $6 b_{1}^{0}$ & $\ldots$ & $\ldots$ \\
\hline 4.443 & $6 a_{1}^{0}$ & 4.442 & $6 a_{1}^{0}$ \\
\hline 4.458 & $18 b_{1}^{0}$ & $\ldots$ & $\ldots$ \\
\hline 4.501 & $16 b_{1}^{1 \mathrm{c}}$ & $\ldots$ & $\ldots$ \\
\hline 4.508 & $0_{0}^{0}$ & 4.507 & $0_{0}^{0}$ \\
\hline$\ldots$ & $\ldots$ & 4.512 & $4_{1}^{0} 5_{0}^{1}$ \\
\hline 4.513 & $?$ & 4.513 & $4_{0}^{1} \tau \mathrm{OH}_{1}^{0}$ \\
\hline 4.548 & $\tau \mathrm{OH}_{1}^{1}$ & 4.548 & $\tau \mathrm{OH}_{1}^{1}$ \\
\hline$\ldots$ & $\ldots$ & 4.554 & $16 a_{0}^{2}$ \\
\hline 4.555 & $18 b_{0}^{1}$ & 4.556 & $18 b_{0}^{1}$ \\
\hline 4.567 & $6 a_{0}^{1}$ & 4.567 & $6 a_{0}^{1}$ \\
\hline 4.577 & $6 b_{0}^{1}$ & $\ldots$ & $\ldots$ \\
\hline $4.60(1)(s)$ & $18 b_{0}^{2}$ & $\ldots$ & $\ldots$ \\
\hline 4.605 & $12_{0}^{1}$ & $\ldots$ & $\ldots$ \\
\hline 4.624 & $6 a_{0}^{2}$ & $\ldots$ & $\ldots$ \\
\hline 4.626 & $18 a_{0}^{1}$ & 4.626 & $18 a_{0}^{1}$ \\
\hline 4.636 & $9 a_{0}^{1}$ & 4.629 & $9 a_{0}^{1}$ \\
\hline 4.649 & $6 b_{0}^{2}$ & $\ldots$ & $\ldots$ \\
\hline $4.65(4)(w)$ & $18 b_{0}^{3}$ & $\ldots$ & $\ldots$ \\
\hline 4.666 & $7 a_{0}^{1}$ & $\ldots$ & $\ldots$ \\
\hline 4.683 & $6 a_{0}^{3} / 6 a_{0}^{1} 12_{0}^{2}$ & $\ldots$ & $\ldots$ \\
\hline 4.702 & $12_{0}^{2}$ & $\ldots$ & $\ldots$ \\
\hline 4.713 & $6 b_{0}^{3}$ & $\ldots$ & $\ldots$ \\
\hline 4.721 & $6 a_{0}^{1} 7 a_{0}^{1}$ & $\ldots$ & $\ldots$ \\
\hline 4.741 & $6 a_{0}^{2} 12_{0}^{2}$ & & \\
\hline 4.763 & $9 a_{0}^{2}$ & $\ldots$ & $\ldots$ \\
\hline 4.781 & $1_{0}^{1} 7 a_{0}^{1} / 6 a_{0}^{2} 7 a_{0}^{1}$ & 4.781 & $1_{0}^{1} 7 a_{0}^{1}$ \\
\hline 4.798 & $12_{0}^{3} / 6 a_{0}^{3} 12_{0}^{2}$ & $\ldots$ & $\ldots$ \\
\hline 4.818 & $1_{0}^{1} 12_{0}^{2}$ & 4.817 & $1_{0}^{1} 12_{0}^{2}$ \\
\hline 4.822 & $7 a_{0}^{2}$ & $\ldots$ & $\ldots$ \\
\hline 4.838 & $6 a_{0}^{3} 7 a_{0}^{1}$ & $\ldots$ & $\ldots$ \\
\hline 4.877 & $6 a_{0}^{1} 7 a_{0}^{2}$ & $\ldots$ & $\ldots$ \\
\hline 4.896 & $12_{0}^{4}$ & $\ldots$ & $\ldots$ \\
\hline
\end{tabular}

a (s) — shoulder feature, (w) — weak feature, (b)—broad structure (the last decimal of the energy value is given in brackets for these less-resolved features). ? feature remains unassigned.

${ }^{\mathrm{b}}$ Vibrational modes notation adopted from Refs. 19 and 22.

${ }^{\mathrm{c}}$ From Ref. 44.

EOM-CCSD level of accuracy (4.947 eV, Table II) gives a better agreement with the experimental data. The adiabatic transition is observed at $4.508 \mathrm{eV}(34.6 \mathrm{Mb})$ in very good agreement with the value of Nix et al. ${ }^{22}$ at $4.507 \mathrm{eV}(275.113$ $\mathrm{nm})$. Vieuxmaire et al. ${ }^{43}$ report an adiabatic excitation energy at $4.612 \mathrm{eV}$ at $\mathrm{CAS}(10,9) / 6-31 \mathrm{G}^{* *}$ level of theory against the experimental value of $4.507 \mathrm{eV}$ according to Bist et al. ${ }^{44}$ and Berden $e t a l .,{ }^{45}$ the latter being a comprehensive study on the structure and dynamics of internal rotation of phenol. We also note that rotationally resolved fluorescence excitation spectra of phenol by Martinez et al. ${ }^{46}$ place the (0-0) transition at $4.507 \mathrm{eV}$. This absorption band shows resolvable rovibronic structure, and assignments are presented in Table III, where 
they are revisited and compared with the detailed data of Nix et $a l .{ }^{22}$ with several new features reported here for the first time.

The present high-resolution spectrum reveals that the fine structure is due to several modes (see Table III for the proposed detailed assignments), with the main contributions from the oxygen stretching motion mode, $v_{6 a}^{\prime}\left(a^{\prime}\right)$, and the $\mathrm{O}-\mathrm{H}$ torsion mode, $v_{6 b}^{\prime}\left(a^{\prime}\right)$. These modes also appear coupled with other modes. Due to the complexity of such fine structure in the absorption band in Fig. 3, and in order to avoid congestion, we have represented a few modes only. It is noteworthy that the normal vibrational description may lead to some Fermi resonances, making assignments particularly difficult. The features below the $0_{0}^{0}$ transition are tentatively assigned to hot-bands based on the previous work of Nix et al. ${ }^{22}$ The feature at $4.548 \mathrm{eV}$ is tentatively assigned as a sequence band of the $\mathrm{OH}$ torsion mode, further to assignments of Nix et al. ${ }^{22}$

\section{Valence and vibronic excitation in the range $5.3-7.0 \mathrm{eV}$}

The lowest valence excitation band in this energy range (Fig. 4) has been assigned to the $\left(1 \pi^{*} \leftarrow 3 \pi+2 \pi^{*} \leftarrow 4 \pi\right)$ transition in agreement with previous reports. ${ }^{16,26}$ The $0_{0}^{0}$ transition is here proposed at $5.75(5) \mathrm{eV}$ (see Table IV). The $1142 \mathrm{~cm}^{-1}(0.142 \mathrm{eV})$ spacing reported by Anderson et al. ${ }^{19}$ for phenol excited states is in very good agreement with the mean value of $0.106 \mathrm{eV}$ (Fig. 4 and Table IV), which has been assigned to the excitation of ring $\mathrm{CH}$ in-plane deformation and CC stretching mode, $v_{9 a}^{\prime}\left(a^{\prime}\right)$ with $1167 \mathrm{~cm}^{-1}(0.145 \mathrm{eV})$ in the neutral ground state. ${ }^{19,22,23,47}$ The next band with the highest oscillator strength $\left(\mathrm{f}_{\mathrm{L}} \approx 0.61\right.$ at TD-DFT level and $\approx 0.39$ at EOM-CCSD), peaking at $6.736 \mathrm{eV}$, has been assigned to $\left(1 \pi^{*} \leftarrow 3 \pi+2 \pi^{*} \leftarrow 4 \pi\right)$ in Table I, whereas in the case of toluene it was reported at $6.786 \mathrm{eV}$ and assigned to a mixed Rydberg/valence $\left(1 \pi^{*} \leftarrow 3 \pi+3 \mathrm{p} \pi\left(\mathrm{a}^{\prime \prime}\right) \leftarrow 2 \pi\right)$. ${ }^{32}$ We note that the calculated vertical excitation energies are obtained more accurately from the calculations at the EOM-CCSD level of theory rather than the TD-DFT (LC-wPBE/aug-cc-pVTZ+R) level when compared to the experimental values (Table II). According to the calculations, the $3 \mathrm{p} \pi\left(\mathrm{a}^{\prime}\right) \leftarrow 3 \pi\left(3 \mathrm{a}^{\prime \prime}\right)$ Rydberg transition has a considerable oscillator strength (0.06) at the EOM-CCSD level and contributes to the feature observed in this energy range. A few quanta of the oxygen stretching motion mode, $v_{6 a}^{\prime}\left(a^{\prime}\right)$, are excited (see Table V) and the $0_{0}^{0}$ transition is proposed at $6.461 \mathrm{eV}$, although we note

TABLE IV. Proposed vibrational assignments in the 5.3-6.3 eV absorption band of phenol, $\mathrm{C}_{6} \mathrm{H}_{5} \mathrm{OH}^{\mathrm{a}}{ }^{\mathrm{a}}$

\begin{tabular}{lcc}
\hline \hline Energy (eV) & Assignment & $\Delta \mathrm{E}(\mathrm{eV})$ \\
\hline $5.75(5)(\mathrm{b})$ & $0_{0}^{0}$ & $\ldots$ \\
$5.85(9)(\mathrm{b})$ & $9_{0}^{1}$ & 0.104 \\
$5.89(3)(\mathrm{b})$ & $\ldots$ & $\ldots$ \\
$6.00(4)(\mathrm{b})$ & $9_{0}^{1}$ & 0.111 \\
$6.10(2)(\mathrm{b}, \mathrm{w})$ & $9_{0}^{2}$ & 0.098 \\
\hline \hline
\end{tabular}

a(b) _broad structure; (w) — weak feature (the last decimal of the energy value is given in brackets for these less-resolved features). a weak feature at $6.401 \mathrm{eV}$. Since the latter lies on an underlying state with a different slope from the rising left-hand side of the most intense absorption feature, we tentatively assign it to the $\sigma^{*}(\mathrm{OH}) \leftarrow 3 \pi\left(3 \mathrm{a}^{\prime \prime}\right)$ transition according to the calculations in Table II, although we do not discard the possibility of another transition, from $3 \mathrm{p} \sigma / \sigma^{*}(\mathrm{OH}) \leftarrow 4 \pi$ and $3 s \sigma / \sigma^{*}(\mathrm{OH}) \leftarrow 3 \pi$, contributing to the spectrum. This energy region exhibits evidence for transitions to Rydberg states at 6.736, 6.91(1), and 7.12(8) eV (see Section V B and Table VI), converging to the ionic electronic first excited and ionic ground states, respectively, and also shows some quanta excitation number of oxygen stretching motion mode, $v_{6 a}^{\prime}\left(a^{\prime}\right)$, (Table $V$ ) with a mean excitation energy of $0.056 \mathrm{eV}$. However, Anderson et al. ${ }^{19}$ pointed out that in the neutral excited states of phenol, the strong absorption band is dominated by two fundamental modes assigned to oxygen stretching modes $v_{6 \mathrm{a}}^{\prime}\left(\mathrm{a}^{\prime}\right)$ and $v_{12}^{\prime}\left(\mathrm{a}^{\prime}\right)$, with excitation energies of 526 and $935 \mathrm{~cm}^{-1}$. Nonetheless, the normal mode vibrational description may lead to Fermi resonances, making assignments particularly difficult. Finally we note in Fig. 4 a rather broad background contribution that can be attributed to a pre-dissociative state. A careful look at Tables I and II shows a rather low oscillator strength $\left(\mathrm{f}_{\mathrm{L}}=0.0002\right.$ in Table II) transition, assigned to $\sigma^{*}(\mathrm{OH}) \leftarrow 4 \pi$ at $\sim 5.75 \mathrm{eV}$ (Fig. 3) and in good agreement with the $S_{2}\left({ }^{1} \pi \sigma^{*}\right)$ state of Livingstone et $a .^{21}$ calculated at $5.55 \mathrm{eV}$ at the EOM-CCSD level.

\section{B. Rydberg transitions}

The VUV photoabsorption spectrum above $6.0 \mathrm{eV}$ consists of a few structures superimposed on a diffuse absorption feature extending to the lowest IEs, which are reported here for the first time. The experimental ionisation energy values of Kishimoto et al. ${ }^{20}$ are used to determine the Rydberg series. The proposed Rydberg structures are labelled in Figs. 4-7 and listed in Table VI. The peak positions have been tested using the Rydberg formula: $E_{n}=E_{i}-R /(n-\delta)^{2}$, where $E_{i}$ is the ionisation energy, $n$ is the principal quantum number of the Rydberg orbital of energy $E_{n}, R$ is the Rydberg constant $(13.61 \mathrm{eV})$, and $\delta$ is the quantum defect resulting from the penetration of the Rydberg orbital into the core. The experimental values for the lowest terms of the $\mathrm{ns}, \mathrm{np}$, and nd $(n=3)$ Rydberg series (Table VI) are in good agreement with the calculations in Table II.

The lowest transition energy is assigned to $3 \mathrm{~s} \sigma / \sigma^{*}(\mathrm{OH})$ $\leftarrow 4 \pi$ at 5.75(5) $\mathrm{eV}$ for the Rydberg series converging to the ionic electronic ground state, with a quantum defect $\delta=0.83$ (Table VI), accompanied by vibronic structure, which is proposed to be mainly due to excitation of ring $\mathrm{CH}$ in-plane deformation and $\mathrm{CC}$ stretching mode, $v^{\prime}{ }_{9}\left(\mathrm{a}^{\prime}\right)$, with an average value of $0.104 \mathrm{eV}$ (Fig. 4 and Table IV) (and even of oxygen stretching motion mode, $\left.v_{6 a}^{\prime}\left(a^{\prime}\right)\right)$, in very good agreement with $0.150 \mathrm{eV}$ for the $\tilde{X}^{2} \mathrm{~A}^{\prime \prime}$ state from the work of Anderson et al. ${ }^{20}$ However, these authors note that this mode is a weakly active mode in the $\mathrm{C}_{6} \mathrm{H}_{5} \mathrm{OH}^{+}$ion. The higher members of this Rydberg series are proposed to extend to $n=7$. Because of the complexity of such fine structure in the absorption band in Fig. 6, and in order to avoid congestion, we have presented only a few modes. 
TABLE V. Proposed vibrational assignments in the $6.2-10.8 \mathrm{eV}$ absorption region of phenol, $\mathrm{C}_{5} \mathrm{H}_{5} \mathrm{OH} .{ }^{\mathrm{a}}$

\begin{tabular}{|c|c|c|c|c|c|}
\hline Energy $(\mathrm{eV})$ & Assignment & $\Delta \mathrm{E}(\mathrm{eV})$ & Energy $(\mathrm{eV})$ & Assignment & $\Delta \mathrm{E}(\mathrm{eV})$ \\
\hline 6.461 & $0_{0}^{0}$ & & 7.690 & $4 d$ & $\ldots$ \\
\hline \multirow[t]{2}{*}{$6.52(2)(\mathrm{s})$} & $6 a_{0}^{1}$ & 0.061 & 7.741 & $4 \mathrm{~d}+6 a_{0}^{1}$ & 0.051 \\
\hline & $\ldots$ & $\ldots$ & 7.799 & $4 \mathrm{~d}+6 a_{0}^{2}$ & 0.058 \\
\hline 6.634 & $6 a_{0}^{3}$ & $\ldots$ & & & \\
\hline $6.68(4)(b)$ & $6 a_{0}^{4}$ & 0.050 & 7.803 & $5 \mathrm{~s} / 4 \mathrm{~s}$ & $\ldots$ \\
\hline 6.735 & $6 a_{0}^{5}$ & 0.051 & 7.858 & $5 \mathrm{~s} / 4 \mathrm{~s}+6 a_{0}^{1}$ & 0.055 \\
\hline 6.790 & $6 a_{0}^{6}$ & 0.055 & & & \\
\hline \multirow[t]{2}{*}{$6.84(8)(\mathrm{s})$} & $6 a_{0}^{7}$ & 0.058 & 7.885 & $5 p$ & $\ldots$ \\
\hline & & & 7.951 & $5 p+6 a_{0}^{1}$ & 0.066 \\
\hline $6.91(1)(\mathrm{s})$ & $3 d$ & $\ldots$ & 8.001 & $5 \mathrm{p}+6 a_{0}^{2}$ & 0.050 \\
\hline $6.96(2)(\mathrm{s}, \mathrm{w})$ & $3 \mathrm{~d}+6 a_{0}^{1}$ & 0.051 & $8.05(6)(w)$ & $5 \mathrm{p}+6 a_{0}^{3}$ & 0.055 \\
\hline \multirow[t]{2}{*}{$7.01(7)(\mathrm{s}, \mathrm{w})$} & $3 \mathrm{~d}+6 a_{0}^{2}$ & 0.055 & & & \\
\hline & & & $7.915(w)$ & $\ldots$ & $\ldots$ \\
\hline $7.39(5)(\mathrm{s})$ & $4 p$ & $\ldots$ & 7.962 & $6 a_{0}^{1}$ & 0.047 \\
\hline 7.44(4) (s) & $4 p+6 a_{0}^{1}$ & 0.049 & 8.007 & $6 a_{0}^{2}$ & 0.045 \\
\hline 7.496 & $4 p+6 a_{0}^{2}$ & 0.052 & & & \\
\hline 7.562 & $4 \mathrm{p}+6 a_{0}^{3} / 3 \mathrm{~d}$ & 0.066 & 8.093 & $6 s$ & $\ldots$ \\
\hline 7.622 & $3 \mathrm{~d}+6 a_{0}^{1}$ & 0.060 & $8.15(2)(\mathrm{s})$ & $6 \mathrm{p} / 6 \mathrm{~s}+6 a_{0}^{1}$ & 0.059 \\
\hline 7.675 & $3 \mathrm{~d}+6 a_{0}^{2}$ & 0.053 & 8.197 & $6 \mathrm{p} / 6 \mathrm{~s}+6 a_{0}^{2}$ & 0.045 \\
\hline \multirow[t]{2}{*}{7.735} & $3 \mathrm{~d}+6 a_{0}^{3}$ & 0.060 & & & \\
\hline & & & 8.429 & $9 \mathrm{~s}$ & $\ldots$ \\
\hline $7.60(6)(\mathrm{s})$ & $\ldots$ & $\ldots$ & $8.50(1)(b)$ & $9 \mathrm{~s}+6 a_{0}^{1}$ & 0.072 \\
\hline $7.66(0)(w)$ & $6 a_{0}^{1}$ & 0.054 & 8.565 & $9 \mathrm{~s}+6 a_{0}^{2} / 5 \mathrm{p}$ & 0.064 \\
\hline 7.711 & $6 a_{0}^{2}$ & 0.051 & & & \\
\hline 7.76(9) (s) & $6 a_{0}^{3}$ & 0.058 & 8.472 & $5 \mathrm{~s}$ & $\ldots$ \\
\hline $7.823(w)$ & $6 a_{0}^{4}$ & 0.054 & $8.52(1)(\mathrm{s})$ & $5 \mathrm{~s}+6 a_{0}^{1}$ & 0.049 \\
\hline \multirow[t]{4}{*}{7.880} & $6 a_{0}^{5}$ & 0.057 & & & \\
\hline & & & $8.84(3)(b)$ & $6 p$ & $\ldots$ \\
\hline & & & $9.00(4)(b)$ & $6 \mathrm{p}+8 a_{0}^{1} / 7 \mathrm{p} / 3 \mathrm{p}$ & 0.161 \\
\hline & & & $9.17(0)(b)$ & $6 \mathrm{p}+8 a_{0}^{2} / 7 \mathrm{p}+8 a_{0}^{1} / 3 \mathrm{p}+8 a_{0}^{1}$ & 0.166 \\
\hline
\end{tabular}

a(s) — shoulder structure, (b) — broad structure, (w) — weak structure (the last decimal of the energy value is given in brackets for these less-resolved features).

The first members of the np and nd series are associated with peaks at 6.00(4) $\mathrm{eV}(\delta=0.73)$ and 6.91(1) $\mathrm{eV}(\delta=0.19)$, respectively (Table VI). The nd series shows an $\mathrm{n}=3$ vibrational excitation with two quanta of ring distortion mode, $v_{6 a}^{\prime}\left(a^{\prime}\right)$, with an average value of $0.053 \mathrm{eV}$ (Fig. 6 and Table V), in very good agreement with $0.059 \mathrm{eV}$ for the $\tilde{X}^{2} \mathrm{~A}^{\prime \prime}$ state from the work of Anderson et al. ${ }^{20}$ The higher members of these Rydberg series, for which the relative intensity decreases, are difficult to assign due to their overlap with other transitions and possible vibronic structure (see Table V). Close to the lowest ionic limit, features tentatively assigned to the ring distortion mode, $v_{6 a}^{\prime}\left(a^{\prime}\right)$, appear quite abundantly.

The first members of the ns, np, and nd series converging to the ionic electronic first excited state of phenol $\left(3 \mathrm{a}^{\prime \prime-1}\right)$ are associated with the peaks at 5.89(3) $\mathrm{eV}(\delta=1.01), 6.736 \mathrm{eV}$ $(\delta=0.70)$, and $7.562 \mathrm{eV}(\delta=0.22)$, respectively (Table VI). The rather high quantum defect for the $3 \mathrm{~s}$ Rydberg member is due to the contribution of the valence $\sigma^{*}(\mathrm{OH})$ state (Table II). The Rydberg transitions (Fig. 6) are accompanied by vibronic structure, which is tentatively attributed to excitation of the $v_{6 a}^{\prime}$ $\left(a^{\prime}\right)$ mode (Table V); however, the normal mode configuration may also lead to Fermi resonances.

As far as members of the Rydberg series converging to the ionic electronic second excited state are concerned, $\mathrm{n}=3$ for ns, np and nd are proposed at 8.178, 9.00(4), and 9.70(9) eV, respectively (Table VI), with quantum defects 1.00, 0.70, and 0.30 , respectively. Some of the fine structure has been assigned to vibrational excitation involving the ring distortion mode $v_{6 a}^{\prime}\left(\mathrm{a}^{\prime}\right)$, as well as ring and $\mathrm{OH}$ bending character, $v_{8 \mathrm{a}}^{\prime}\left(\mathrm{a}^{\prime}\right)$, the latter in good agreement with the photoelectron spectrum of Anderson et al.,$^{20}$ although we were able to assign new features (see Table VI and Fig. 7).

We have not made any attempt to identify higher members $(n>3)$ of the Rydberg series, due to the broad and structureless nature of the absorption bands. Note that the clear increase in the absorption with energy, in the range above $9.0 \mathrm{eV}$, may be related to low-lying pre-dissociative or dissociative excited neutral states.

\section{Absolute photoabsorption cross-sections and atmospheric photolysis}

The present optical measurements were carried out in the pressure range $0.02-0.43 \mathrm{mbar}$ and reveal no evidence for changes in absolute cross sections or peak energies as a function of pressure, thus we believe that the present spectra are free of any saturation effects. Previous absolute VUV photoabsorption cross sections of phenol are available in the wavelength ranges $244-283 \mathrm{~nm}(4.38-5.08 \mathrm{eV}),{ }^{12} 245-285 \mathrm{~nm}$ 
TABLE VI. Energy value $(\mathrm{eV})$, quantum defect $(\delta)$, and assignment of the Rydberg series converging to the ionic electronic ground $\left(4 a^{\prime \prime-1}\right)$, first $\left(3 a^{\prime \prime-1}\right)$, and second $\left(2 \mathrm{a}^{\prime \prime-1}\right)$ excited states of phenol, $\mathrm{C}_{6} \mathrm{H}_{5} \mathrm{OH}{ }^{\mathrm{a}}$

\begin{tabular}{lccccc}
\hline \hline $\mathrm{E}_{\mathrm{n}}$ & $\delta$ & Assignment & $\mathrm{E}_{\mathrm{n}}$ & $\delta$ & Assignment \\
\hline $\mathrm{IE}_{1}=8.64 \mathrm{eV}$ & & & $\mathrm{IE}_{2}=9.32 \mathrm{eV}$ & & \\
$5.75(5)(\mathrm{b})$ & 0.83 & $3 \mathrm{~s}$ & $5.89(3)(\mathrm{s})$ & 1.01 & $3 \mathrm{~s}$ \\
$7.12(8)(\mathrm{b}, \mathrm{w})$ & 1.00 & $4 \mathrm{~s}$ & 7.803 & 1.00 & $4 \mathrm{~s}$ \\
7.803 & 0.97 & $5 \mathrm{~s}$ & 8.472 & 0.99 & $5 \mathrm{~s}$ \\
8.093 & 1.01 & $6 \mathrm{~s}$ & & & \\
8.263 & 0.99 & $7 \mathrm{~s}$ & 6.736 & 0.70 & $3 \mathrm{p}$ \\
8.363 & 0.99 & $8 \mathrm{~s}$ & 8.072 & 0.70 & $4 \mathrm{p}$ \\
8.429 & 0.97 & $9 \mathrm{~s}$ & 8.565 & 0.75 & $5 \mathrm{p}$ \\
& & & $8.84(3)(\mathrm{b})$ & 0.66 & $6 \mathrm{p}$ \\
$6.00(4)$ & 0.73 & $3 \mathrm{p}$ & $9.00(4)(\mathrm{b})$ & 0.44 & $7 \mathrm{p}$ \\
$7.39(5)(\mathrm{s})$ & 0.69 & $4 \mathrm{p}$ & & & \\
7.885 & 0.75 & $5 \mathrm{p}$ & 7.562 & 0.22 & $3 \mathrm{~d}$ \\
$8.15(2)(\mathrm{s})$ & 0.72 & $6 \mathrm{p}$ & 8.400 & 0.15 & $4 \mathrm{~d}$ \\
8.299 & 0.68 & $7 \mathrm{p}$ & $8.74(7)(\mathrm{s}, \mathrm{w})$ & 0.13 & $5 \mathrm{~d}$ \\
& & & & & \\
$6.91(1)(\mathrm{s})$ & 0.19 & $3 \mathrm{~d}$ & $\mathrm{IE}_{3}=11.57 \mathrm{eV}$ & & \\
7.690 & 0.21 & $4 \mathrm{~d}$ & 8.178 & 1.00 & $3 \mathrm{~s}$ \\
8.040 & 0.24 & $5 \mathrm{~d}$ & & & \\
8.233 & 0.22 & $6 \mathrm{~d}$ & $9.00(4)(\mathrm{b})$ & 0.70 & $3 \mathrm{p}$ \\
8.346 & 0.20 & $7 \mathrm{~d}$ & & & \\
& & & $9.70(9)(\mathrm{b})$ & 0.30 & $3 \mathrm{~d}$ \\
& & & & &
\end{tabular}

$\overline{\overline{\text { a }(\mathrm{b}) \text {-broad structure, (w) —-weak structure, (s)—shoulder structure (the last decimal of }}}$ the energy value is given in brackets for these less-resolved features).

$(4.35-5.06 \mathrm{eV}),{ }^{13} \quad 200-290 \mathrm{~nm} \quad(4.28-6.20 \mathrm{eV}),{ }^{14}$ and 160-240 nm (5.17-7.75 eV). ${ }^{15}$ Etzkorn et al.,${ }^{12}$ Trost et al. ${ }^{13}$ Grosch et al. ${ }^{14}$ and Kimura and Nagakura ${ }^{15}$ reported absolute cross sections of magnitude $19.8 \mathrm{Mb}(275.1 \mathrm{~nm}, 4.51 \mathrm{eV})$, $\sim 37 \mathrm{Mb}(275 \mathrm{~nm}, 4.51 \mathrm{eV}), \sim 19.1 \mathrm{Mb}(275 \mathrm{~nm}, 4.51 \mathrm{eV})$, and $36.1 \mathrm{Mb}(6.82 \mathrm{eV})$, compared to the present value of $34.6 \mathrm{Mb}$ at $4.508 \mathrm{eV}$. Such differences, as in the case of Etzkorn et al., ${ }^{12}$ are mainly attributable to experimental resolution, where a value of $0.15 \mathrm{~nm}$ is reported, against the present value of $0.075 \mathrm{~nm}$. We have noted over the last decade an excellent agreement of previous cross sections measured on the UV1 beam line on ASTRID with the most precise data available in the literature (see the work of Eden et al. ${ }^{48}$ and references therein and more recently Ref. 49). This indicates that the present absolute phenol cross sections are reliable over the energy range studied (4.3-10.8 eV).

The present absolute cross sections below $6.89 \mathrm{eV}$ (above $180 \mathrm{~nm}$ ) can be used in combination with solar actinic flux ${ }^{50}$ measurements from the literature to estimate the photolysis rate of phenol in the atmosphere from an altitude close to the ground to the stratopause at $50 \mathrm{~km}$. Details of the calculation programme are presented in Ref. 51, in which the quantum yield for dissociation following absorption is assumed to be unity. The reciprocal of the photolysis rate at a given altitude corresponds to the local photolysis lifetime. Photolysis lifetimes of around 24 sunlit hours were calculated at ground level, with less than an hour above $30 \mathrm{~km}$. This shows that phenol molecules can be broken up quite efficiently by UV absorption even at low altitudes. From the ground level up to the tropopause, the lifetimes can be low, such that photolysis may be a sink mechanism. However, the rate coefficients obtained by Trost et al. ${ }^{13}$ for reactions between the $\mathrm{OH}$ radical and phenol have shown that this may provide a main reactive sink mechanism in the troposphere. Moreover, night time reactivity of $\mathrm{NO}_{3}$ radicals with phenol can be also regarded as an important sink mechanism. ${ }^{10}$ Therefore, compared with radical reactions, UV photolysis is not expected to play a significant role in the tropospheric removal of phenol molecules.

\section{CONCLUSIONS}

The present work provides the first comprehensive study to date of the VUV electronic spectroscopy of phenol and provides the most reliable set of absolute photoabsorption cross sections between 4.3 and $10.8 \mathrm{eV}$. The observed valence and Rydberg transitions have been assigned with the help of $a b$ initio calculations on the vertical excitation energies and oscillator strengths at two different levels of accuracy. The theoretical results are in good agreement with the experiments, predicting significant mixing of Rydberg and $\pi^{*}$ states, and allowed for novel assignments in the photon energy covered in this work which have not been previously reported in the literature. The state at $6.401 \mathrm{eV}$ is tentatively assigned for the first time to the $\sigma^{*}(\mathrm{OH}) \leftarrow 3 \pi\left(3 \mathrm{a}^{\prime \prime}\right)$ transition. The analysis of the observed vibronic structure in the photoabsorption spectra is generally consistent with earlier data, although the higher resolution of the present experiments has enabled us to propose for the first time assignments for the valence and Rydberg excitations. The photolysis lifetimes of phenol have also been carefully derived for the earth's troposphere and stratosphere and show that solar photolysis is expected to be a weak sink in the terrestrial atmosphere.

\section{ACKNOWLEDGMENTS}

P.L.V. and F.F.S. acknowledge the Portuguese National Funding Agency FCT-MCTES through Grant Nos. UID/FIS/00068/2013 and IF-FCT IF/00380/2014. E.L. acknowledges the Brazilian Agency Conselho Nacional de Desenvolvimento Científico e Tecnológico (CNPq) and the Science Without Borders Programme for opportunities to study abroad. D.D. acknowledges support from the CaPPA project (Chemical and Physical Properties of the Atmosphere), funded by the French National Research Agency (ANR) through the PIA (Programme d'Investissement d'Avenir) under Contract No. ANR-10-LABX-005 and by the Regional Council "Nord-Pas de Calais" and the "European Funds for Regional Economic Development" (FEDER). M.A.Ś. would like to acknowledge the Visiting Research Fellow position at The Open University. This work was performed using HPC resources from GENCI-CINES (Grant No. 2015-088620). The Centre de Ressources Informatiques (CRI) of the Université of Lille also provided computing time. The authors wish to acknowledge the beam time at the ISA synchrotron at Aarhus University, Denmark. We also acknowledge the financial support provided by the European Community's Seventh Framework Programme (No. FP7/2007-2013) CALIPSO 
under Grant Agreement No. 312284. M.J.B. acknowledges financial support provided through the Australian Research Council (ARC).

${ }^{1}$ A. J. Ragauskas, C. K. Williams, B. H. Davison, G. Britovsek, J. Cairney, C. A. Eckert, W. J. Frederick, J. P. Hallett, D. J. Leak, C. L. Liotta, J. R. Mielenz, R. Murphy, R. Templer, and T. Tschaplinski, Science 311, 484 (2006).

${ }^{2}$ M. E. Himmel, S. Y. Ding, D. K. Johnson, W. S. Adney, M. R. Nimlos, J. W. Brady, and T. D. Foust, Science 315, 804 (2007).

${ }^{3}$ G. M. Roberts, A. D. Chatterley, J. D. Young, and V. G. Stavros, J. Phys. Chem. Lett. 3, 348 (2012).

${ }^{4}$ A. I. Sobolewski, W. Domcke, C. Dedonder-Lardeux, and C. Jouvet, Phys. Chem. Chem. Phys. 4, 1093 (2002).

${ }^{5}$ M. N. R. Ashfold, G. A. King, D. Murdock, M. G. D. Nix, T. A. A. Oliver, and A. G. Sage, Phys. Chem. Chem. Phys. 12, 1218 (2010).

${ }^{6}$ M. N. R. Ashfold, B. Cronin, A. L. Devine, R. N. Dixon, and M. G. D. Nix, Science 312, 1637 (2006).

${ }^{7}$ M. N. R. Ashfold, A. L. Devine, R. N. Dixon, G. A. King, M. G. D. Nix, and T. A. A. Oliver, Proc. Natl. Acad. Sci. U. S. A. 105, 12701 (2008).

${ }^{8}$ O. P. J. Vieuxmaire, Z. Lan, A. L. Sobolewski, and W. Domcke, J. Phys. Chem. 129, 224307 (2008).

${ }^{9}$ S. G. Ramesh and W. Domcke, Faraday Discuss. 163, 73 (2013).

${ }^{10}$ R. Atkinson, W. P. L. Carter, C. N. Plum, A. M. Winer, and J. N. Pitts, Jr., Int. J. Chem. Kinet. 16, 887 (1984).

${ }^{11}$ R. G. Derwent, M. E. Jenkin, and S. M. Saunders, Atmos. Environ. 30, 181 (1996).

${ }^{12}$ T. Etzkorn, B. Klotz, S. Sørensen, I. V. Patroescu, I. Barnes, K. H. Becker, and U. Platt, Atmos. Environ. 33, 525 (1999).

${ }^{13}$ B. Trost, J. Stutz, and U. Platt, Atmos. Environ. 31, 3999 (1997).

${ }^{14}$ H. Grosch, Z. Sárossy, H. Egsgaard, and A. Fateev, J. Quant. Spectrosc. Radiat. Trans. 156, 17 (2015).

${ }^{15}$ K. Kimura and S. Nagakura, Mol. Phys. 9, 117 (1965).

${ }^{16}$ J. Lorentzon, P.-Å. Malmqvist, M. Fulscher, and B. O. Roos, Teor. Chim. Acta 91, 91 (1995).

${ }^{17}$ M. Miura, Y. Aoki, and B. Champagne, J. Chem. Phys. 127, 084103 (2007).

${ }^{18}$ T. Ari, H. Güven, and N. Ecevit, J. Electron Spectrosc. Relat. Phenom. 73, 13 (1995).

${ }^{19}$ S. L. Anderson, L. Goodman, K. K. Jespersen, A. G. Ozkabak, R. N. Zare, and C.-F. Zheng, J. Chem. Phys. 82, 5329 (1985).

${ }^{20}$ N. Kishimoto, M. Furuhashi, and K. Ohno, J. Electron Spectrosc. Relat. Phenom. 113, 35 (2000).

${ }^{21}$ R. A. Livingstone, J. O. F. Thompson, M. Iljina, R. J. Donaldson, B. J. Sussman, M. J. Paterson, and D. Townsend, J. Chem. Phys. 137, 184304 (2012), and references therein.

${ }^{22}$ M. G. D. Nix, A. L. Devine, B. Cronin, R. N. Dixon, and M. N. R. Ashfold, J. Chem. Phys. 125, 133318 (2006).

${ }^{23}$ H. Lampert, W. Mikenda, and A. Karpfen, J. Phys. Chem. A 101, 2254 (1997).

${ }^{24}$ G. Y. Gor, S. Tapio, A. V. Domanskaya, M. Räsänen, A. V. Nemukhin, and L. Khriachtchev, Chem. Phys. Lett. 517, 9 (2011).

${ }^{25}$ S. J. Martinez III, J. C. Alfano, and D. H. Levy, J. Mol. Spectrosc. 152, 80 (1992).

${ }^{26}$ D. B. Jones, G. B. da Silva, R. F. C. Neves, H. V. Duque, L. Chiari, E. M. de Oliveira, M. C. A. Lopes, R. F. da Costa, M. T. do N. Varella, M. H. F. Bettega, M. A. P. Lima, and M. J. Brunger, J. Chem. Phys. 141, 074314 (2014).

${ }^{27}$ R. F. C. Neves, D. B. Jones, M. C. A. Lopes, K. L. Nixon, G. B. da Silva, H. V. Duque, E. M. de Oliveira, R. F. da Costa, M. T. do. N. Varella, M. H. F. Bettega, M. A. P. Lima, K. Ratnavelu, G. García, and M. J. Brunger, J. Chem. Phys. 142, 104305 (2015).

${ }^{28}$ R. F. C. Neves, D. B. Jones, M. C. A. Lopes, K. L. Nixon, E. M. de Oliveira, R. F. da Costa, M. T. do. N. Varella, M. H. F. Bettega, M. A. P. Lima, G. B. da Silva, and M. J. Brunger, J. Chem. Phys. 142, 194302 (2015).

${ }^{29}$ R. F. C. Neves, D. B. Jones, M. C. A. Lopes, F. Blanco, G. García, K. Ratnavelu, and M. J. Brunger, J. Chem. Phys. 142, 194305 (2015)
${ }^{30}$ R. F. da Costa, E. M. de Oliveira, M. H. F. Bettega, M. T. do N. Varella, D. B. Jones, M. J. Brunger, F. Blanco, R. Colmenares, P. Limão-Vieira, G. García, and M. A. P. Lima, J. Chem. Phys. 142, 104304 (2015).

${ }^{31}$ G. B. da Silva, R. F. C. Neves, L. Chiari, D. B. Jones, E. Ali, D. H. Madison, C. G. Ning, K. L. Nixon, M. C. A. Lopes, and M. J. Brunger, J. Chem. Phys. 141, 124307 (2014).

${ }^{32}$ C. Serralheiro, D. Duflot, F. Ferreira da Silva, S. V. Hoffmann, N. C. Jones, N. J. Mason, B. Mendes, and P. Limaõ-Vieira, J. Phys. Chem. A 119, 9059 (2015).

${ }^{33}$ O. A. Vydrov and G. E. Scuseria, J. Chem. Phys. 125, 234109 (2006).

${ }^{34}$ O. A. Vydrov, J. Heyd, A. V. Krukau, and G. E. Scuseria, J. Chem. Phys. 125, 074106 (2006).

${ }^{35}$ O. A. Vydrov, G. E. Scuseria, and J. P. Perdew, J. Chem. Phys. 126, 154109 (2007).

${ }^{36}$ M. J. Frisch, G. W. Trucks, H. B. Schlegel, G. E. Scuseria, M. A. Robb, J. R. Cheeseman, G. Scalmani, V. Barone, B. Mennucci, G. A. Petersson, H. Nakatsuji, M. Caricato, X. Li, H. P. Hratchian, A. F. Izmaylov, J. Bloino, G. Zheng, J. L. Sonnenberg, M. Hada, M. Ehara, K. Toyota, R. Fukuda, J. Hasegawa, M. Ishida, T. Nakajima, Y. Honda, O. Kitao, H. Nakai, T. Vreven, J. A. Montgomery, Jr., J. E. Peralta, F. Ogliaro, M. J. Bearpark, J. Heyd, E. N. Brothers, K. N. Kudin, V. N. Staroverov, R. Kobayashi, J. Normand, K. Raghavachari, A. P. Rendell, J. C. Burant, S. S. Iyengar, J. Tomasi, M. Cossi, N. Rega, N. J. Millam, M. Klene, J. E. Knox, J. B. Cross, V. Bakken, C. Adamo, J. Jaramillo, R. Gomperts, R. E. Stratmann, O. Yazyev, A. J. Austin, R. Cammi, C. Pomelli, J. W. Ochterski, R. L. Martin, K. Morokuma, V. G. Zakrzewski, G. A. Voth, P. Salvador, J. J. Dannenberg, S. Dapprich, A. D. Daniels, Ö. Farkas, J. B. Foresman, J. V. Ortiz, J. Cioslowski, and D. J. Fox, Gaussian 09, Gaussian, Inc., Wallingford, CT, USA, 2009.

${ }^{37}$ T. H. Dunning, Jr., J. Chem. Phys. 90, 1007 (1989).

${ }^{38}$ K. Kaufmann, W. Baumeister, and M. Jungen, J. Phys. B 22, 2223 (1989).

${ }^{39}$ R. L. Martin, J. Chem. Phys. 118, 4775 (2003).

${ }^{40}$ H.-J. Werner, P. J. Knowles, G. Knizia, F. R. Manby, M. Schütz, P. Celani, T. Korona, R. Lindh, A. Mitrushenkov, G. Rauhut, K. R. Shamasundar, T. B. Adler, R. D. Amos, A. Bernhardsson, A. Berning, D. L. Cooper, M. J. O. Deegan, A. J. Dobbyn, F. Eckert, E. Goll, C. Hampel, A. Hesselmann, G. Hetzer, T. Hrenar, G. Jansen, C. Köppl, Y. Liu, A. W. Lloyd, R. A. Mata, A. J. May, S. J. McNicholas, W. Meyer, M. E. Mura, A. Nicklaß, D. P O'Neill, P. Palmieri, D. Peng, K. Pflüger, R. Pitzer, M. Reiher, T. Shiozaki, H. Stoll, A. J. Stone, R. Tarroni, T. Thorsteinsson, and M. Wang, Molpro, version 2006.1, a package of ab initio programs, 2006, see http://www.molpro.net.

${ }^{41}$ S. Eden, P. Limão-Vieira, S. V. Hoffmann, and N. J. Mason, Chem. Phys. 323, 313 (2006).

${ }^{42}$ M. H. Palmer, T. Ridley, S. V. Hoffmann, N. C. Jones, M. Coreno, M. de Simone, C. Grazioli, M. Biczysko, A. Baiardi, and P. Limão-Vieira, J. Chem. Phys. 142, 134302 (2015).

${ }^{43}$ O. P. J. Vieuxmaire, Z. Lan, A. L. Sobolewski, and W. Domcke, J. Chem. Phys. 129, 224307 (2008).

${ }^{44}$ H. D. Bist, J. C. D. Brand, and D. R. Williams, J. Mol. Spectrosc. 24, 413 (1967).

${ }^{45}$ G. Berden, W. L. Meerts, M. Schmitt, and K. Kleinermanns, J. Chem. Phys. 104, 972 (1996).

${ }^{46}$ S. J. Martinez III, J. C. Alfano, and D. H. Levy, J. Mol. Struct. 152, 80 (1992),

${ }^{47}$ B. M. Giuliano, I. Reva, L. Lapinski, and R. Fausto, J. Chem. Phys. 136, 024505 (2012).

${ }^{48}$ S. Eden, P. Limão-Vieira, S. V. Hoffmann, and N. J. Mason, Chem. Phys. 331, 232 (2007).

${ }^{49}$ M. A. Śmiałek, M. Łabuda, J. Guthmuller, M.-J. Hubin-Franskin, J. Delwiche, D. Duflot, N. J. Mason, S. V. Hoffmann, N. C. Jones, and P. LimãoVieira, J. Chem. Phys. 141, 104311 (2014).

${ }^{50}$ W. B. DeMore, S. P. Sander, D. M. Golden, R. F. Hampson, M. J. Kurylo, C. J. Howard, A. R. Ravishankara, C. E. Kolb, and M. J. Molina, Chemical Kinetics and Photochemical Data for Use in Stratospheric Modelling, Evaluation No. 12, 15 January 1997.

${ }^{51}$ P. Limão-Vieira, S. Eden, P. Kendall, N. J. Mason, and S. V. Hoffmann, Chem. Phys. Lett. 364, 535 (2002).

${ }^{52}$ M. B. Robin, Chem. Phys. Lett. 119, 33 (1985).

${ }^{53}$ D. Duflot, S. Zeggari, and J.-P. Flament, Chem. Phys. 327, 518 (2006). 